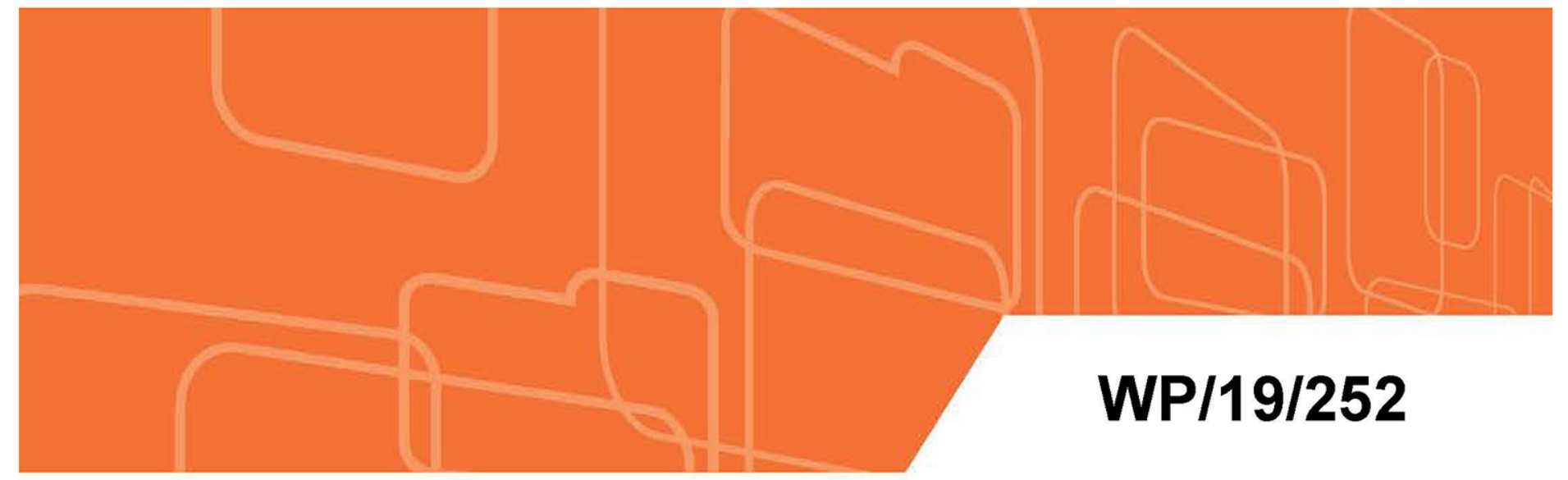

\title{
Designing Central Bank Digital Currencies
}

by Itai Agur, Anil Ari and Giovanni Dell'Ariccia

IMF Working Papers describe research in progress by the author(s) and are published to elicit comments and to encourage debate. The views expressed in IMF Working Papers are those of the author(s) and do not necessarily represent the views of the IMF, its Executive Board, or IMF management. 


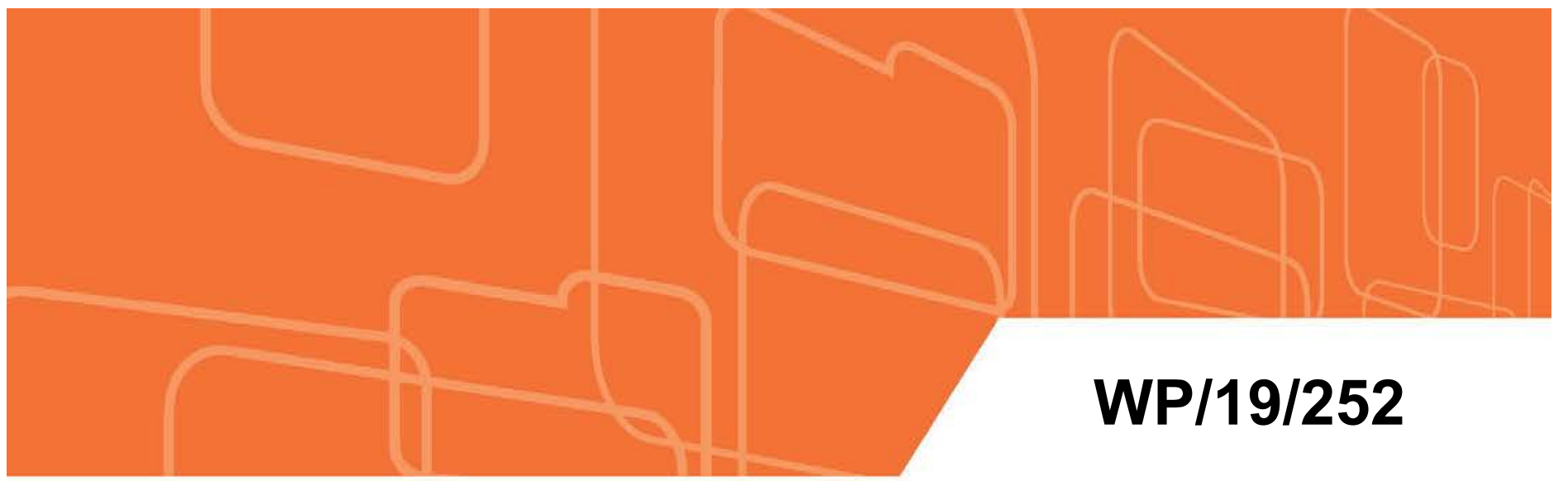

\section{IMF Working Paper}

\section{Designing Central Bank Digital Currencies}

by Itai Agur, Anil Ari and Giovanni Dell'Ariccia

IMF Working Papers describe research in progress by the author(s) and are published to elicit comments and to encourage debate. The views expressed in IMF Working Papers are those of the author(s) and do not necessarily represent the views of the IMF, its Executive Board, or IMF management.

I N T E R N A T I O N A L M O N E T A R Y F U N D 


\title{
IMF Working Paper
}

Research Department

\section{Designing Central Bank Digital Currencies ${ }^{1}$}

\section{Prepared by Itai Agur, Anil Ari and Giovanni Dell'Ariccia}

Authorized for distribution by Giovanni Dell'Ariccia

November 2019

\section{IMF Working Papers describe research in progress by the author(s) and are published to elicit comments and to encourage debate. The views expressed in IMF Working Papers are those of the author(s) and do not necessarily represent the views of the IMF, its Executive Board, or IMF management.}

\begin{abstract}
We study the optimal design of a central bank digital currency (CBDC) in an environment where agents sort into cash, CBDC and bank deposits according to their preferences over anonymity and security; and where network effects make the convenience of payment instruments dependent on the number of their users. CBDC can be designed with attributes similar to cash or deposits, and can be interest-bearing: a CBDC that closely competes with deposits depresses bank credit and output, while a cash-like CBDC may lead to the disappearance of cash. Then, the optimal CBDC design trades off bank intermediation against the social value of maintaining diverse payment instruments. When network effects matter, an interest-bearing CBDC alleviates the central bank's tradeoff.
\end{abstract}

JEL Classification Numbers: E41, E58, G21

Keywords: CBDC, Fintech, Digital currency, Financial intermediation, Network effects.

Author's E-Mail Address: iagur@imf.org; aari@imf.org; gdellariccia@imf.org

\footnotetext{
${ }^{1}$ We would like to thank Todd Keister, Morten Bech, Maria Soledad Martinez Peria, Tommaso ManciniGriffoli, Marcello Miccoli, Beat Weber, Baozhong Yang, Jacky So, Garth Baughman, and audiences at the IMF, the Federal Reserve, the Bank of England, the ECB, the Bank of Israel, Cambridge University, the 12th Paul Woolley Centre Conference, the 12th Swiss Winter Conference on Financial Intermediation, the 19th FDIC/JFSR Conference, the ONB/BIS/CEBRA Conference on Digital Currencies, the Atlanta Fed Conference on the Financial System of the Future, the ADBI Conference on Fintech, the IMF's 2nd Annual Macro-Finance Conference, and the RESMF-FRBIF Workshop on Financial Cycles and Central Banking for helpful comments.
} 


\section{Introduction}

Payment systems and, more fundamentally, money are evolving rapidly. Developments in digital networks and information technology and the increasing share of internet-based retailing have created the demand and technological space for peer-to-peer digital transactions that have the potential to radically change payment and financial intermediation systems. Central banks have been pondering whether and how to adapt. Many are exploring the idea of issuing central bank digital currency (CBDC) - a new type of fiat money that expands digital access to central bank reserves to the public at large, instead of restricting it to commercial banks. ${ }^{1}$ A CBDC would combine the digital nature of deposits with the peer-to-peer transactions use of cash. But would it also resemble deposits by coming in the form of an account at the central bank, or would it come closer to cash, materializing as a digital token? Would it pay interest rates like a bank deposit, or would its nominal return be fixed at naught, like cash? ${ }^{2}$ In this paper, we build a theoretical framework geared at analyzing the relationship between CBDC design, the demand for money types, and financial intermediation.

Swings in the usage of payment instruments become particularly disruptive in the presence of network effects. For example, with declining cash use, banks may cut back on ATMs or shops may refuse to accept cash, a process currently underway in Sweden (Sveriges Riksbank, 2018b). Because of such network effects, payment instruments may disappear when their use falls below a critical threshold, and the successful introduction of a CBDC could risk tipping the balance. Network effects are a critical feature of the model in this paper.

Our starting point is a (static) economy with banks, firms and households. In this economy, banks collect deposits, extend credit to firms, and create social value in doing so: firms' projects are worth less if they cannot receive bank loans. ${ }^{3}$ Both banks and firms engage in perfect competition.

Households face a Hotelling linear-city, where they aim to minimize the distance between the available forms of money and their preferences. In particular, households have heterogeneous preferences over anonymity and security in payments. We represent these preferences by an interval with cash and deposits at opposite ends: cash provides anonymity in transactions, while bank deposits are more secure. ${ }^{4}$ A CBDC can take any point on this interval, depending on its de-

\footnotetext{
${ }^{1}$ For an overview of ongoing CBDC initiatives, see Mancini-Griffoli et al. (2018), Bank for International Settlements (2018) and Prasad (2018). In a survey of 63 central banks, a third of central banks perceived CBDC as a possibility in the medium term (Barontini and Holden, 2019). Notably, the central banks of China, Norway, Sweden, and Uruguay are actively investigating the possibility of introducing a CBDC. The Sveriges Riksbank is expected to decide on the introduction of an eKrona in 2019, while Uruguay's central bank has run a successful pilot (Bergara and Ponce, 2018; Norges Bank, 2018; Sveriges Riksbank, 2018a).

${ }^{2}$ See Mancini-Griffoli et al. (2018) for other design aspects of CBDCs, which are mostly of an operational nature, such as the means to disseminate, secure and clear CBDCs.

${ }^{3}$ We parameterize and vary the degree to which bank financing of firms provides efficiency gains. On the special role of depository institutions in intermediation, see Diamond and Rajan (2001) and Donaldson et al. (2018), as well as Merrouche and Nier (2012) for supporting empirical evidence.

${ }^{4}$ Empirical research on payment instruments choice attributes a central role to heterogeneous preferences (Wakamori and Welte, 2017). For empirical work measuring preferences for anonymity and the potential demand for CBDC, see Athey et al. (2017), Borgonovo et al. (2018) and Masciandaro (2018).
} 
sign. For instance, a central bank could provide partial anonymity (e.g., towards third-parties but not the authorities), set transaction limits below which anonymity is retained, or make anonymity conditional, only to be lifted under court order - possibilities under consideration in central banks' CBDC studies (Mancini-Griffoli et al., 2018).

Overall, taking into account the design of the CBDC, households optimally sort into different types of money according to three considerations: firstly, their (heterogeneous) preferences; secondly, network effects, which derive from the relation between the convenience of using a payment instrument and the number of its users; and thirdly, the interest rates offered on deposits and possibly on CBDC.

Our framework provides novel and policy-relevant insights for welfare analysis and optimal CBDC design. In our model, variety in payment instruments increases welfare because of heterogeneity in household preferences. CBDC then has social value due to its ability to blend features of cash and deposits. As emphasized by Lagarde (2018), there is potential demand for partially anonymous means of payment that can, for example, protect consumers from the use of personal transactions data for credit assessments. ${ }^{5}$

At the same time, introducing a CBDC has welfare costs to the extent that it crowds out demand for cash and deposits. ${ }^{6}$ Specifically, a cash-like CBDC can reduce cash demand beyond the point where network effects cause the disappearance of cash. But a deposit-like CBDC design causes an increase in deposit and loan rates, and a contraction in bank lending to firms. Because of relationship lending frictions, this decline in bank intermediation also curtails investment and output. $^{7}$

We show that the welfare-optimal CBDC design hinges on whether the CBDC is interest-bearing, and whether network effects matter. When the CBDC is not interest-bearing, its similarity to cash becomes the sole design instrument. The more important the role of banks in alleviating lending frictions, the more cash-like the optimal CBDC design becomes. But network effects twist the optimal design problem, as the variety of payment instruments that households value becomes challenging to sustain. A nonlinear optimal design pattern then emerges: Increasing the value added of banks translates into a more cash-like optimal design up to a point, after which CBDC design is constrained to preserve cash. This is so, unless bank-based intermediation is sufficiently precious that the CBDC is introduced with a design that eliminates cash, and replaces it with a less than fully anonymous CBDC.

As long as network effects do not constrain policy, the CBDC interest rate is best kept at zero, because it brings about price distortions in the households' choice of payment instruments. Dif-

\footnotetext{
${ }^{5}$ This possibility is increasingly enabled by technological developments, as for instance discussed by Yao (2018) in the Chinese context, and forms the basis for the microfoundations that we develop in Appendix D.

${ }^{6}$ Nevertheless, a CBDC is certain to raise aggregate welfare in our framework, but only if it is optimally designed. Moreover, even when aggregate welfare rises, there are distributional effects, and some households are worse off due to CBDC availability. We analyze these distributional effects in Section 3.3.

${ }^{7} \mathrm{~A}$ central bank could attempt to mitigate the decline in bank lending by providing banks with cheap liquidity to replace lost deposits. However, this may not be feasible for two reasons. First, banks' ability to intermediate funds may depend on their reliance on deposits (see e.g., Diamond and Rajan, 2001; Donaldson et al., 2018). Second, this policy would permanently expose the central bank to credit risk.
} 
ferent from the interest rates on bank deposits, there is no production underlying the payment of the CBDC interest rate, which is funded with a lump-sum tax. Hence, the CBDC interest rate is a suboptimal tool compared to the design of CBDC payment attributes, which optimally center on meeting some households' demand.

However, access to an adjustable CBDC interest rate makes a palpable difference to the central bank when network effects come to the fore. If the introduction of a CBDC threatens cash with extinction, a negative CBDC interest rate can compensate. ${ }^{8}$ Indeed, when households care enough about payment instrument variety, the interest-bearing CBDC will optimally always keep cash alive, while limiting the CBDC's impact on bank intermediation. This is a finding of policy relevance, since all ongoing central bank CBDC initiatives center on non interest-bearing CBDCs.

In several extensions, we investigate whether considerations other than network effects can cause optimal CBDC rates to diverge from zero. Alternate production functions make no difference. In contrast, bank market power in lending matters, as it entices the central bank to make the CBDC compete harder with deposits, leading optimal CBDC rates to diverge from zero, regardless of network effects. The same is true in another extension, in which households dislike anonymity in other households' payments. That is, there are negative externalities associated with anonymity in payments, because this may spur illicit activities. Once more, giving the central bank an additional ball to juggle - here, counteracting the negative externality - leads to the conclusion that welfare is strictly higher when the CBDC is interest-bearing. In a final extension, we provide a model where households choose between cash and deposit-based payment services that are bundled to the provision of other services (e.g., credit provision related to transactions data), to microfound a linear-city of payment preferences, and to highlight the potential demand for a CBDC that straddles existing payments attributes.

Our paper is closely related to a recent and growing literature on CBDCs. A strand of this literature focuses on the impact of introducing a CBDC on the banking sector. Andolfatto (2018) and Chiu et al. (2019) develop models where CBDC raises welfare by reducing banks' deposit market power, while Brunnermeier and Niepelt (2019), Kim and Kwon (2019) and Miccoli (2019) model the relationship between banking panics and the availability of CBDC. ${ }^{9}$ In Keister and Sanches (2019), CBDC contributes to efficiency in exchange at the expense of crowding out deposits.

Compared to this literature, our first contribution is to highlight a tradeoff between preserving variety in payment instruments in the face of network effects, and mitigating the adverse effects of CBDC on financial intermediation. Our second contribution is to show when and why this tradeoff is harder to overcome with a non interest-bearing CBDC than with a CBDC that offers an

\footnotetext{
${ }^{8}$ Beyond satisfying household preferences, the disappearance of cash may reduce economic activity when a portion of the population is unable or unwilling to transact with digital payment methods because of digital illiteracy or informality. See Chodorow-Reich et al. (2018) for an empirical assessment of such costs.

${ }^{9}$ There is also a sizeable policy literature discussing the financial stability effects of CBDC (see, e.g., Bech and Garratt, 2017; Fung and Halaburda, 2016; He et al., 2017; Kahn et al., 2019).
} 
adjustable interest rate. ${ }^{10}$

Our paper also relates to the literatures on payment systems and network effects. Our modeling of network effects follows closely on the seminal work of Katz and Shapiro (1985). While Katz and Shapiro (1985) study firms' decisions to introduce mutually compatible products, we focus on a social planner's decision to introduce and design a new payment instrument. In the literature on payments systems, the analysis and measurement of network effects centers on credit and debit card networks (Bounie et al., 2017; Chakravorti, 2010; Rochet and Tirole, 2006). ${ }^{11}$ Instead, we study the impact of a new form of money on demand for existing payment instruments and welfare. Finally, the value of variety in payments bears similarity to the value of product variety in international trade (Krugman, 1979). However, our model does not build on an assumed love of variety, but rather on a heterogeneity in preferences that is best served by variety.

The remainder of the paper is organized as follows. Section 2 presents the model. Section 3 analyzes optimal CBDC design. Section 4 concludes. The extensions of the model can be found in the appendices.

\section{A model of payment instruments}

We consider a financial economy populated by households, banks, firms, and a central bank that aims to maximize welfare. Events unfold over two stages. In the first stage, the central bank decides whether and in what form to introduce a CBDC. In the second stage, households choose between holding cash, bank deposits and (if introduced) CBDC for their transactions, and banks use deposits collected from households to extend loans to firms, which in turn produce a consumption good.

Along with the rate of interest offered (if any), households value two attributes in payment instruments - anonymity and security - with heterogeneous preferences over their relative importance. At the core of our model lies a tension between these two attributes, because delinking transactions from personal identity leads to a loss of traceability that creates risks for the holder. For example, while depository accounts are relatively safe and traceable, cash is vulnerable to accidental loss and theft. ${ }^{12}$ It is precisely the fact that cash can be lost without any claim that also makes it perfectly anonymous.

\footnotetext{
${ }^{10}$ In our framework, CBDC interest rates embody any type of subsidy or cost associated with holding CBDC. For example, the pilot conducted by the central bank of Uruguay offered subsidies to CBDC holders (Bergara and Ponce, 2018). Moreover, we focus on the steady state effects of CBDC rates on financial intermediation and cash use, rather than their implications for monetary policy over the business cycle. On the relationship between CBDC and monetary transmission, see Agarwal and Kimball (2015, 2019), Assenmacher and Krogstrup (2018), Barrdear and Kumhof (2016), Bordo and Levin (2017), Bjerg (2017), Davoodalhosseini (2018), Goodfriend (2016), Meaning et al. (2018), and Niepelt (2019).

${ }^{11}$ The role of strategic coordination and adoption equilibria has also been considered in the literature on cryptocurrencies (Biais et al., 2019, 2018; Bolt and Van Oordt, 2019).

${ }^{12}$ We abstract from default risk on bank deposits, which is negligible in normal times due to deposit insurance and implicit bailout guarantees.
} 
This intrinsic link between the degree of anonymity of a means of payment and the difficulty of keeping it safe extends to the realm of digital money. A CBDC can only approach the anonymity of cash if it takes the form of a token, such as a cryptocurrency, which is accessible through user accounts that are not independently verified, or a nameless payment card that can be purchased at stores or online. These forms of CBDC would also suffer from the risks of loss and theft associated with cash, either physically (e.g., card loss) or digitally (e.g., the untraceable loss of account information). At the other extreme, an account at the central bank that can be opened only using official identification would mimic the security and traceability of bank deposits. Different from cash and deposits, however, CBDC can be designed to blend intermediate amounts of anonymity and security. ${ }^{13}$ For example, anonymity may be preserved vis-à-vis third-parties only, and transactions can be recorded but not accessed by the central bank unless a transaction size limit is breached and/or there is suspicion of wrongdoing.

We formalize these considerations in an anonymity-security scale $[0,1]$, where higher values denote a greater extent of anonymity and, equivalently, a lesser degree of security. If we let $x_{j}$ denote the place of each money type $j$ in the anonymity-security scale, cash (denoted with $c$ ) is placed at the top of the scale $x_{c}=1$, deposits (denoted with $d$ ) are at the bottom $x_{d}=0$, and CBDC is placed at $x_{c b d c}=\theta$, where $\theta \in[0,1]$ is a design parameter determined by the central bank. In addition, the central bank determines the (net) interest rate offered on the CBDC, $r_{c b d c}$, which we allow to take any (positive, zero or negative) value. The combination $\left(\theta, r_{c b d c}\right)$ thus describes CBDC design in our framework.

There are two important frictions in the model economy: relationship lending frictions and network externalities in payment transactions. Relationship lending frictions take the form of information asymmetries that bar households from lending directly to firms, which are endowed with positive net present value projects that require financing. Firms may then either rely on intermediation by banks or liquidate their projects. The importance of bank intermediation is proportionate to the gap between firm productivity $A$ and the liquidation value of firm projects $\phi$. When $(A-\phi)$ is higher, a given decline in bank deposits and credit leads to a sharper reduction in output and consumption.

Network externalities give rise to a disutility cost for relying on a payment instrument that is not commonly used. We denote with $\eta_{j}$ the disutility cost from using a money type $j$ and adopt the functional form

$$
\begin{gathered}
\eta_{j}=\max \left\{0, g\left(s_{j}\right)\right\} \forall j \in\{c, c b d c, d\} \\
g(1)<0, g(0)>0, g^{\prime}(.)<-1
\end{gathered}
$$

where $s_{j}$ stands for the share of households holding a money type $j$. The functional form for $\eta_{j}$ is restrictive in two ways. First, we implicitly assume that, for a given share of users $s_{j}$, network externalities are equivalent across different money types. Second, the maximum operator and the restrictions on $g($.$) imply that network externalities only take hold when the share of households$ using a money type falls short of a threshold. We find it convenient to define this threshold as

\footnotetext{
${ }^{13}$ While some legal jurisdictions allow for deposit accounts that offer a degree of anonymity, these accounts are typically incompatible with payments services. Moreover, providing anonymity in deposits may undermine their complementarity with relationship lending (see e.g., Donaldson et al., 2018).
} 
$\underline{s} \equiv g^{-1}(0)$, where $0<\underline{s}<1$. Once network externalities come into play, the restriction $g^{\prime}()<$. -1 ensures that they lead to a cascade: each household that switches to a different money type incentivizes another to switch until the money type falls out of use. This setup helps preserve tractability by eliminating unstable equilibria and ensuring that the equilibrium shares of money types that remain in use are not affected by network externalities.

Below, we explain the activities of households, banks, firms and the central bank in further detail. We then proceed to characterize the equilibria and conduct welfare analysis.

\subsection{Agents and their optimal strategies}

\subsubsection{Households}

There is a unit continuum of households with preferences $i \in[0,1]$ uniformly distributed over the anonymity-security scale. ${ }^{14}$ Households start with identical endowments in terms of (atomistic) shares in firms and liquid funds which are normalized to 1 . Liquid funds are stored in a money type $j \in\{c, d, c b d c\}$ and used to purchase the consumption good at the end of the stage..$^{15}$ Most importantly, households cannot attain their preference $i$ by mixing different forms of money in their transactions because a transaction is only as anonymous as the least anonymous payment instrument used. In other words, anonymity is undiversifiable. ${ }^{16}$

The household budget constraint is given by

$$
C_{j}=1+r_{j}-T+\pi
$$

where $C_{j}$ is consumption, $\pi$ represents dividends from firm profits, $r_{j}$ is the (net) interest earned on money holdings such that

$$
r_{j}=\left\{\begin{array}{l}
0 \quad \text { if } j=c \\
r_{c b d c} \text { if } j=c b d c \\
r_{d} \quad \text { if } j=d
\end{array}\right.
$$

and $T=r_{c b d c} s_{c b d c}$ is a lump-sum tax used to fund interest rates on CBDC (or equivalently a lump-sum transfer to redistribute revenues when $\left.r_{c b d c}<0\right) .{ }^{17}$

The households' utility maximization problem can then be written as

$$
\max _{j \in\{c, d, c b d c\}} U_{i}(j)=\rho C_{j}-\left|x_{j}-i\right|-\eta_{j}
$$

\footnotetext{
${ }^{14}$ We adopt a uniform distribution for the sake of tractability. Our qualitative results generalize to any single peaked distribution with continuous support and sufficient weight in the tails to ensure that, absent a CBDC, both deposits and cash are sustained as payment instruments.

${ }^{15}$ We assume that all forms of money are traded on par.

${ }^{16}$ This notion is further explored in Appendix D, which provides an example of how a Hotelling linear-city setup of payments preferences can be microfounded.

${ }^{17}$ This can be interpreted as a zero-capital central bank: any revenue that the central bank makes is immediately paid out to households, and any capital shortfall arising from CBDC costs directly leads to a recapitalization through a lump-sum tax.
} 
subject to the budget constraint (2). Here, $\left|x_{j}-i\right|$ represents the utility cost of selecting a payment method that differs from the household's anonymity-security preference $i$ while $\rho>0$ denotes the marginal utility of consumption relative to payment preferences. ${ }^{18}$ Network effects are captured by $\eta_{j}$, as defined by (1). The solution to the household's problem yields the following cut-off conditions for a household with preferences $i$ to choose

$$
\begin{aligned}
& \text { cash over CBDC : } \quad 1-i+\eta_{c}<|\theta-i|-\rho r_{c b d c}+\eta_{c b d c} \\
& \text { cash over deposits : } 1-i+\eta_{c}<i-\rho r_{d}+\eta_{d} \\
& \text { CBDC over deposits : }|\theta-i|-\rho r_{c b d c}+\eta_{c b d c}<i-\rho r_{d}+\eta_{d}
\end{aligned}
$$

\subsubsection{Banks}

Banks collect deposits $d$ from households at net deposit rate $r_{d}$ and extend loans $l$ to firms at net loan rate $R$, with the budget constraint

$$
l=d
$$

The representative bank is risk neutral and a price-taker in both deposit and loan markets such that its profit maximization problem yields the first order condition

$$
r_{d}=R
$$

which simply equates interest rates on deposits and loans. ${ }^{19}$

\subsubsection{Firms}

Firms are perfectly competitive and begin with an identical endowment of productive projects $k_{0}$ which require financing to implement. ${ }^{20}$ The representative firm uses bank loans $l$ to finance a portion of projects $k=l$. Once implemented, these projects yield a payoff in terms of consumption goods with the technology

$$
Y=\left(A-\frac{k}{2}\right) k
$$

\footnotetext{
${ }^{18}$ The manner in which we combine consumption with payment preferences bears similarity to the utility function adopted in Gopinath and Stein (2018).

${ }^{19}$ See Appendix C.3 for an extension where we allow for market power in the bank loans market.

${ }^{20}$ We impose the restriction $k_{0}>1$ to ensure that lending frictions always bind such that $k<k_{0}$.
} 
where $A>1$ denotes productivity. ${ }^{21}$ The remaining projects $\left(k_{0}-k\right)$ are liquidated at a constant rate of return $\phi \in(0,1) .^{22}$

The representative firm's profit maximization problem can then be written as

$$
\max _{k, l} Y+\phi\left(k^{0}-k\right)-(1+R) l
$$

subject to (10) and $k=l$. This yields the first order condition

$$
1+R=A-\phi-l
$$

which can be interpreted as a downward sloping loan demand curve. Notably, a decline in the liquidation value $\phi$ raises firm demand for loans, reflecting the increased importance of bank intermediation. More generally, we can refer to $(A-\phi)$ as 'the value added from bank intermediation,' since it captures the value generated by channeling funds to firms with productivity $A$, instead of having the firms sell off their projects at value $\phi$. One can think of this from a crosscountry perspective, where some countries are more reliant on bank-based intermediation and others less so, since in some countries relationship lending frictions are easier to overcome by alternate (i.e., nonbank) means.

\subsubsection{Central bank}

The central bank aims to maximize social welfare, defined as the sum of household utilities

$$
W=\int_{i \in[0,1]} U_{i}\left(j^{*}(i)\right) d i
$$

where $j^{*}(i)$ denotes the payment instrument selected by household $i$. In doing so, the central bank decides whether to introduce a CBDC, and if introduced, its design characteristics $\left(\theta, r_{c b d c}\right){ }^{23}$ If a CBDC is introduced, the central bank's design problem is given by

$$
\max _{\theta \in[0,1], r_{c b d c}} \int_{i \in[0,1]} U_{i}\left(j^{*}(i)\right) d i
$$

\footnotetext{
${ }^{21}$ We adopt a quadratic functional form in the interest of tractability. Appendix C.1 considers a constant returns to scale technology as an alternative. In a derivation available upon request, we also generalize the quadratic technology to the form $Y=\left(A-\Gamma \frac{k}{2}\right) k$ and show that results are robust to varying $\Gamma$.

${ }^{22}$ The liquidation value is also in terms of consumption goods. The liquidation of projects can be microfounded in a framework similar to Stein (2012) where projects are sold to outside buyers with a lower marginal valuation. While we do not explicitly incorporate outside buyers into our model, doing so would have no impact on welfare provided these buyers are non-resident and/or projects are priced at their opportunity cost to outside buyers. In the interest of tractability, we also assume that funds from liquidated projects cannot be used towards financing other projects. This could be due to a combination of information asymmetries and timing. For example, the time required for outside buyers to verify and pay for a project may exhaust the time for implementation by firms.

${ }^{23} \mathrm{An}$ implicit assumption in our model is that the central bank does not allow any agent to take a short position in CBDC (i.e., the central bank does not grant CBDC credit to other parties). This precludes arbitrage opportunities by entities without payment preferences, such as banks, which might prefer funding themselves with CBDC rather than deposits. Based on CBDC studies currently underway at central banks, we consider this a realistic assumption.
} 
subject to a design constraint

$$
s_{c b d c} \geq \underline{s}
$$

which ensures that there is sufficient take-up of the CBDC to overcome network effects. ${ }^{24}$

\subsection{Equilibrium and welfare}

A competitive equilibrium where deposit, loan and capital markets clear, is given by

$$
s_{d}=d=l=k
$$

The interaction of network externalities with the three money types in our framework leads to a rich set of equilibrium types, as shown in Table 1 below. In the interest of brevity, we introduce the parameter restrictions

$$
1<(A-\phi) \leq \frac{5}{2} ; \quad \frac{3}{4} \leq \rho \leq \frac{3}{2} ; \quad \underline{s} \leq \frac{1}{17}
$$

which allow us to focus our discussions on "well-behaved" equilibria that give rise to plausible outcomes. For instance, when there is no CBDC, we should observe that deposits and cash are able to coexist, as they do in most countries. ${ }^{25,26}$ We also bring forward a number of results based on optimal CBDC designs that are formally derived later in the paper. Lemma 1 shows that an optimally designed CBDC always raises welfare. Therefore, the central bank always prefers to introduce a CBDC. Lemma 2 shows that the CBDC design constraint does not bind, while deposits remain in use under an optimal CBDC design.

Lemma 1 Under optimal policies derived in Section 3, the introduction of an optimally-designed $C B D C$ always raises social welfare.

\section{Proof. Provided in Appendix A.}

\footnotetext{
${ }^{24}$ The design constraint subsumes two conditions, $r_{c b d c} \geq-(1-\theta) \rho^{-1}$ and $\theta>\rho\left(r_{d}-r_{c b d c}\right)$, which respectively rule out the strict dominance of CBDC by cash and deposits (i.e., ensure that neither cash nor deposits offer all households a strictly better utility than CBDC) as per (5) and (7). For example, a completely cash-like CBDC $(\theta=1)$ that pays negative rates $\left(r_{c b d c}<0\right)$ would violate the first condition, such that all households have a strict preference for cash over CBDC. Because of network externalities, these conditions are necessary, but not sufficient, for positive CBDC take-up.

${ }^{25}$ While our model is not quantitative in nature, empirical evidence suggests that network effects only begin to play a significant role when the use of a payments instrument becomes very small, as respresented by $\underline{s} \leq \frac{1}{17}$. For instance, in Canada, cash is widely accepted although only about 10 percent of transactions in value terms are conducted with cash (Engert et al., 2018). In contrast, in Sweden, where network effects on cash are becoming a source of concern, cash use stands near 1 percent of transactions value (Sveriges Riksbank, 2017). We discuss the outcome when cash demand is too low to sustain cash, even absent the introduction of CBDC, at the end of Section 3.1.

${ }^{26}$ The restriction $(A-\phi)>1$ ensures that aggregate output (and hence consumption) increases in financial intermediation in equilibrium. This follows directly from the derivative $\frac{d Y}{d k}$, which, given $k \leq 1$, is always positive for $(A-\phi)>1$.
} 
Table 1: Possible equilibria and role in discussion

\begin{tabular}{|c|c|}
\hline Equilibrium & Role in discussion \\
\hline Deposits \& Cash \& CBDC & Referred to as ce \\
Deposits \& CBDC & Referred to as nce \\
Deposits \& Cash & Never occurs under optimal policy \\
CBDC \& Cash & Never occurs under optimal policy \\
CBDC only & Never occurs under optimal policy \\
Cash only & Impossible under any policy \\
Deposits only & Impossible under any policy \\
\hline
\end{tabular}

Lemma 2 Under optimal policies derived in Section 3, the parameter restrictions in (17) imply that $s_{d} \geq \underline{s}$ and $s_{c b d c} \geq \underline{s}$.

Proof. Provided in Appendix A.

As indicated by Table 1, the parameter restrictions and optimality results allow us to narrow down the set of possible equilibria to just two well-behaved equilibria: a 'cash equilibrium' (denoted by ce) where all three money types are in use, and a 'cashless equilibrium' (denoted by $n c e$ ) where cash disappears and only deposits and CBDC remain in use. ${ }^{27}$

Cash equilibrium In the cash equilibrium, cash use remains high enough to prevent network externalities from causing its disappearance. Using the properties of the uniform distribution, (5)(7) can be solved to attain the shares of households holding each money type, which are

$$
\begin{aligned}
s_{c}^{c e} & =\frac{1-\theta-\rho r_{c b d c}}{2} \\
s_{d}^{c e} & =\frac{\rho\left(r_{d}-r_{c b d c}\right)+\theta}{2} \\
s_{c b d c}^{c e} & =\frac{1-\rho r_{d}}{2}+\rho r_{c b d c}
\end{aligned}
$$

Cashless equilibrium In the cashless equilibrium, network externalities lead to the disappearance of cash such that $s_{c}^{n c e}=0$, in which case the shares of households holding CBDC and deposits become

$$
\begin{aligned}
s_{d}^{n c e} & =\frac{\rho\left(r_{d}-r_{c b d c}\right)+\theta}{2} \\
s_{c b d c}^{n c e} & =1-\frac{\rho\left(r_{d}-r_{c b d c}\right)+\theta}{2}
\end{aligned}
$$

${ }^{27}$ The three equilibria referred to as never occurring under optimal policy are further discussed in Appendix C.4, which considers outcomes under suboptimal CBDC design. The equilibria referred to as "impossible under any policy" are ruled out by the parameter restrictions which imply that, when there is no CBDC, the lowest possible shares of deposits and cash, respectively, are inf $s_{d}=\frac{7}{22}$ and inf $s_{c}=\frac{3}{22}$, both of which are above $\underline{s}$. The derivations for these results are available upon request. 
Observe from (19) and (21) that the expressions for the shares of deposit holders are same in the two equilibrium types $\left(s_{d}^{c e}=s_{d}^{n c e}\right)$. This is because, when there is a CBDC, deposits do not directly compete with cash. By (16), the expressions for deposit (and loan) interest rates, firm production and aggregate consumption are also the same in both equilibrium types and given by

$$
\begin{aligned}
r_{d} & =\frac{2(A-1-\phi)-\left(\theta-\rho r_{c b d c}\right)}{2+\rho} \\
s_{d} & =\frac{\rho\left(A-1-\phi-r_{c b d c}\right)+\theta}{2+\rho} \\
Y & =\left(A-\frac{s_{d}}{2}\right) s_{d} \\
\int_{i \in[0,1]} C_{j^{*}(i)} d i & =1+\phi k_{0}+\left(A-\phi-1-\frac{s_{d}}{2}\right) s_{d}
\end{aligned}
$$

where $s_{d}$ represents the share of deposits after substituting out for $r_{d}$. Notably, regardless of the equilibrium type, the introduction of a CBDC that competes closely with deposits through a deposit-like design (i.e., low $\theta$ ) and/or by offering high interest rates $r_{c b d c}$ crowds out bank deposits. Although banks partially offset this by offering higher deposit rates $r_{d}$, in equilibrium this brings about a decline in bank intermediation, which also reduces firm production and aggregate consumption as per (25) and (26). The extent of the decline in aggregate consumption depends on relationship lending frictions. When these frictions are stronger (i.e., $A-\phi$ is larger), a given decline in $s_{d}$ leads to a larger fall in aggregate consumption. This is precisely why we refer to $(A-\phi)$ as the value added from bank intermediation.

Finally, it is important to note that network externalities lead to strategic complementarities in households' payment decisions, thus bringing about the possibility of multiplicity between cash and cashless equilibria. However, both of these equilibrium types may also arise due to fundamentals, and multiplicity does not lead to insights that are interesting, or that we observe in reality. Therefore, we rule out multiplicity by assuming that it is always resolved in favor of a cash equilibrium, which we consider to be similar to the pre-digital currency economy. A cashless equilibrium then arises only when fundamentals are such that the cash equilibrium is not selfconfirming, which is the case when the boundary condition

$$
s_{c}^{c e} \geq \underline{s}
$$

is violated. ${ }^{28}$ Using (18), we can also write this condition in terms of CBDC design parameters as

$$
\theta+\rho r_{c b d c} \leq 1-2 \underline{s}
$$

which indicates that a CBDC that competes strongly with cash through a cash-like design (i.e., high $\theta$ ) and/or by offering a sufficiently high interest rate $r_{c b d c}$ may eliminate cash and give rise to a cashless equilibrium. We proceed with a discussion of the resulting comparative statics.

\footnotetext{
${ }^{28}$ Resolving multiplicity in favor of the cashless equilibrium shifts the boundary condition to $\theta+\rho r_{c b d c}>1-$ $2 \underline{s}-g(0)$ without any qualitative impact on our analysis.
} 


\section{Figure 1: Comparative statics of money shares}
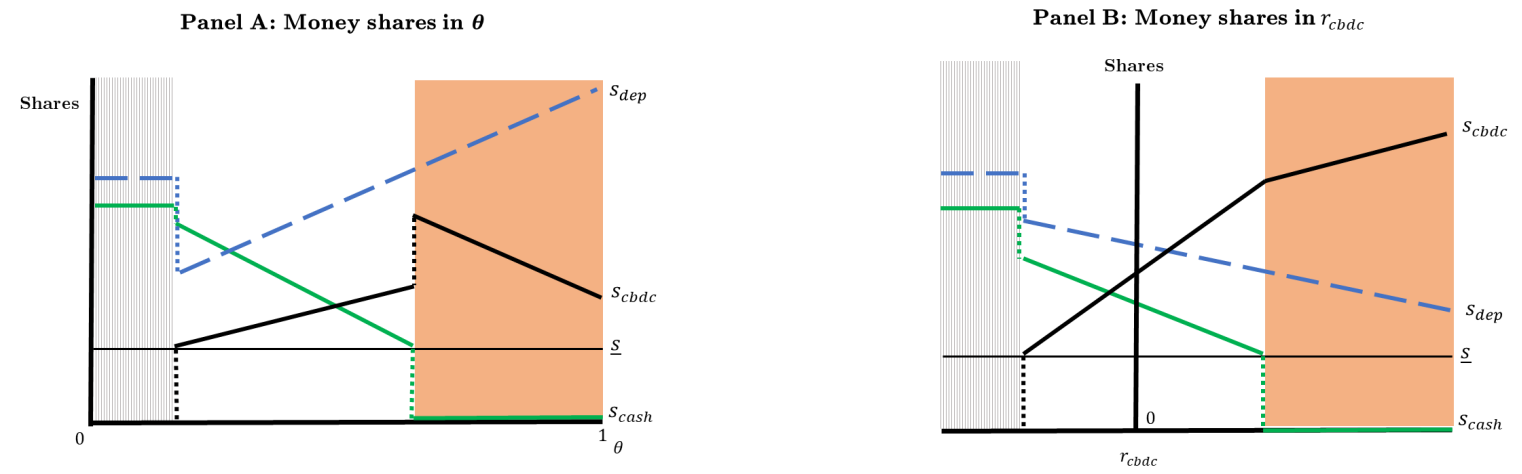

Note: Shares and equilibrium boundaries are drawn according to (18)-(28).

\subsubsection{Comparative statics}

Figure 1 depicts the comparative statics of money shares in terms of CBDC design parameters $\left(\theta, r_{c b d c}\right)$. The unshaded part of Panel A shows that cash holdings decline and bank deposits rise as the CBDC becomes more cash-like with higher $\theta$. Notably, the share of CBDC holders rises as the CBDC becomes more cash-like. This is because banks respond to reduced competition from CBDC by lowering deposit rates $r_{d}$, whereas cash offers no interest. However, when CBDC becomes sufficiently cash-like such that cash use declines below a threshold $\underline{s}$, network externalities lead to a cashless equilibrium, depicted by the shaded area at the right end of Panel $\mathrm{A}$. This leads to a jump up in CBDC use, because cash holders switch to CBDC. As CBDC becomes even more cash-like, households with preferences on the margin between CBDC and bank deposits switch to the latter, thereby raising deposits and reducing CBDC use. Panel B shows that a higher CBDC rate $r_{c b d c}$ reduces the shares of both cash and deposits, while raising that of CBDC. However, as banks raise deposit rates in response to higher $\mathrm{CBDC}$ rates, deposits decline less than cash. A sufficiently high $r_{c b d c}$ leads to a cashless equilibrium, which is depicted by the shaded area at the right end of the panel. Furthermore, the striped areas at the left ends of Panel A and B represent domains where the CBDC design constraint is violated, and CBDC falls out of use.

Finally, note that we can analyze the impact of introducing a CBDC with a given design $\left(\theta, r_{c b d c}\right)$ by comparing it with the equilibrium under a CBDC that is completely cash-like $(\theta=1)$ and offers no interest $\left(r_{c b d c}=0\right)$. With this design, the CBDC is identical to cash and becomes completely innocuous in our model. In other words, introducing a CBDC is like moving $\theta$ from 1 to a lower value and/or changing $r_{c b d c}$ away from 0 . Once the CBDC moves away from cash mimicry, the combination $\left(\theta, r_{c b d c}\right)$ needs to be competitive enough if the CBDC is to have a positive uptake (as represented by the CBDC design constraint). Moreover, as compared to a world without CBDC, any such positive uptake of CBDC necessarily derives from both cash and deposits in our model. That is, introducing a CBDC always brings about some decline in banks' deposit base and consequently in bank intermediation to firms, although the extent of this effect depends on how closely the CBDC competes with deposits. To the extent that the CBDC reduces bank intermediation, it also causes a decline in aggregate output and consumption. 


\subsubsection{Welfare analysis}

In equilibrium, social welfare can be split into two terms

$$
W=\rho \int_{i \in[0,1]} C_{j^{*}(i)}-\left|x_{j^{*}(i)}-i\right| d i
$$

The first term represents aggregate consumption as given by (26). Because of the role of banks in providing firm financing, aggregate consumption relates closely to the extent of bank intermediation, and therefore to bank deposits $s_{d}$. The second term $\left|x_{j^{*}(i)}-i\right|$ represents welfare losses due to the distance between households' payment preferences and their preferred instrument. This term embodies the social value of variety in payment instruments, as increased variety provides heterogeneous households with greater opportunity to minimize the distance to their payment preferences.

How these two terms affect welfare, particularly in relation to CBDC design instruments $\theta$ and $r_{c b d c}$, becomes clearer in the closed form expressions for welfare provided in Lemma 3.

Lemma 3 Social welfare in the cash and cashless equilibria are respectively given by

$$
\begin{aligned}
W^{c e}\left(\theta, r_{c b d c}\right) & =\frac{4 \rho\left(A-\phi-\frac{1}{2}\right) \theta+4(1-\theta) \theta-3 \rho \theta^{2}-(4+\rho) \rho^{2} r_{c b d c}^{2}+\omega_{1}}{4(2+\rho)} \\
W^{n c e}\left(\theta, r_{c b d c}\right) & =\frac{2 \rho(A-\phi) \theta+(4-3 \theta) \theta-2 \rho \theta^{2}-\rho^{2} r_{c b d c}^{2}+\omega_{2}}{2(2+\rho)}
\end{aligned}
$$

where $\omega_{1}$ and $\omega_{2}$ are collections of constants

$$
\begin{aligned}
& \omega_{1} \equiv \rho\left(7+4 k_{0} \phi(2+\rho)+\rho\left(6+2 A^{2}-4 A(1+\phi)+2 \phi(2+\phi)\right)\right)-2 \\
& \omega_{2} \equiv \rho^{2}\left(3+A^{2}-2 A(1+\phi)+\phi\left(2+2 k_{0}+\phi\right)\right)+\rho\left(3+4 k_{0} \phi\right)-2
\end{aligned}
$$

Proof. Provided in Appendix A.

To provide intuition, we focus on the breakdown of the terms in the first expression (30) which pertains to welfare under the cash equilibrium, although a similar breakdown applies to (31) and the cashless equilibrium as well.

The first term $4 \rho\left(A-\phi-\frac{1}{2}\right) \theta$ captures the relation between the value of bank intermediation $(A-\phi)$ and CBDC design characteristic $\theta$. When $(A-\phi)$ is greater, aggregate consumption and social welfare depend more strongly on the intermediation derived from bank deposits. This, in turn, calls for a CBDC that competes less intensely with banks, through a more cash-like CBDC design (i.e., high $\theta$ ).

The second and third terms, $4(1-\theta) \theta-3 \rho \theta^{2}$, pertain to the relation between variety in payment instruments and CBDC design. Notably, these terms are linear-quadratic in $\theta$, meaning they have 
an interior maximum, and this captures the fact that variety in payment instruments is best served by an intermediate CBDC design that is differentiated from both cash and deposits.

The final term $-(4+\rho) \rho^{2} r_{c b d c}^{2}$, is negative and quadratic in $r_{c b d c}$, with the implication that a non interest-bearing CBDC maximizes welfare within a given equilibrium type. This is because an interest-bearing CBDC distorts households' payment choices away from the instrument closest to their payment preferences. As this affects households on the margin between CBDC and another instrument, these distortions rise at an increasing rate as $r_{c b d c}$ moves further from zero. Moreover, different from deposit rates, payment choice distortions caused by $r_{c b d c}$ are not offset by a contribution to financial intermediation. While deposit rates reflect the surplus from increased bank lending and the resulting rise in firm production, CBDC rates are funded by lump-sum transfers that have no direct productive impact.

Finally, it is important to note that by focusing on welfare within a given type of equilibrium, our discussion has so far abstracted from network effects and the associated equilibrium determination condition (28). Accounting for these effects, social welfare is given by

$$
W\left(\theta, r_{c b d c}\right)=\left\{\begin{array}{l}
W^{c e}\left(\theta, r_{c b d c}\right) \text { if } \theta+\rho r_{c b d c} \leq 1-2 \underline{s} \\
W^{n c e}\left(\theta, r_{c b d c}\right) \text { otherwise }
\end{array}\right.
$$

and CBDC design parameters $\left(\theta, r_{c b d c}\right)$ may lead to a switch from one equilibrium type to another. In the next section, we shed more light on optimal CBDC design, including the role of the $\mathrm{CBDC}$ in interest rate, in the presence of network effects.

\section{Optimal CBDC design}

In this section, we analyze the optimal CBDC design which maximizes social welfare, proceeding in two steps. First, we investigate the optimal design of a non interest-bearing CBDC, and then how optimization of an interest-bearing CBDC differs from this.

This two-step approach is more than a matter of analytical convenience. In practice, most central banks appear to be constraining themselves to non interest-bearing CBDCs. This may be due to political economy considerations, such as concerns about a central bank liability that is held by the general public and can be made to pay negative interest. Alternatively, there could be legal hurdles to an interest-bearing CBDC. For instance, the need to tax positive interest earnings may interfere with a desire to offer a degree of anonymity on the CBDC in certain jurisdictions (Engert and Fung, 2017). Using our framework, we can analyze the economic ramifications of constraining the CBDC to a non interest-bearing form. 


\subsection{Non interest-bearing CBDC}

When a CBDC is required to be non interest-bearing $\left(r_{c b d c}=0\right)$, the design optimization problem is given by

$$
\max _{\theta \in[0,1]}\{W(\theta, 0)\}
$$

where $W(\theta, 0)$ is defined according to (34) and Lemma $3 .{ }^{29}$ Accordingly, the optimal CBDC design in the cash and cashless equilibria can be solved to

$$
\begin{aligned}
\theta^{c e} & =\frac{2+\rho(2(A-\phi)-1)}{4+3 \rho} \\
\theta^{n c e} & =\frac{2+\rho(A-\phi)}{3+2 \rho}
\end{aligned}
$$

where the parameter restrictions (17) ensure that $\theta^{c e}$ and $\theta^{\text {nce }}$ are well-defined on $[0,1] .^{30}$ The implication is that optimal policy leads to an interior CBDC design where CBDC's cash-likeness equates the marginal benefit on bank intermediation with marginal losses to payments system variety from moving too close to cash. Furthermore, combining these expressions with (30) and (31) shows that, as long as network effects play no role, the cash equilibrium welfare dominates the cashless equilibrium such that

$$
W^{c e}\left(\theta^{c e}, 0\right)-W^{n c e}\left(\theta^{\text {nce }}, 0\right)=\frac{(\rho(A-\phi-2)-1)^{2}}{2(3+2 \rho)(4+3 \rho)}>0
$$

where the inequality is strict because $\rho(A-\phi-2) \neq 1$ given our parameter assumptions. This dominance of the cash equilibrium derives from the fact that payment instrument variety creates social value for heterogeneous households. If sustaining that variety is costless, welfare is best served by having all three payment instruments in use.

However, network effects impose costs on maintaining cash use by "constraining" the CBDC design optimization. In particular, when applied to a non interest-bearing CBDC, the condition (28) can be written as an upper bound on the degree to which the CBDC approximates cash,

$$
\bar{\theta} \leq 1-2 \underline{s}
$$

above which the economy moves to a cashless equilibrium. That is, whenever $\theta^{c e}>\bar{\theta}$, the choice is no longer between $W^{c e}\left(\theta^{c e}, 0\right)$ and $W^{\text {nce }}\left(\theta^{\text {nce }}, 0\right)$, since the latter is no longer implementable: A CBDC with design $\theta^{c e}$ is too cash-like and would reduce cash use below the threshold $\underline{s}$ where network effects cause cash demand to spiral down to zero. Instead, optimization centers on $W^{c e}(\bar{\theta}, 0)$ versus $W^{\text {nce }}\left(\theta^{\text {nce }}, 0\right)$, that is, preserving the cash equilibrium under a CBDC design constrained at $\bar{\theta}$ versus allowing cash to vanish and having unconstrained optimal policy with only CBDC and deposits in existence. Defining $\Theta$ as optimal policy when taking into account the constraint imposed by network effects, we obtain Figure 2.31

\footnotetext{
${ }^{29}$ The design constraint (15) is slack under optimal policies as per Lemma 2.

${ }^{30}$ Given (17), these optimal policies can range between $\theta^{\text {ce }} \in\left[\frac{7}{17}, \frac{16}{17}\right]$ and $\theta^{\text {nce }} \in\left[\frac{7}{12}, \frac{23}{24}\right]$.

${ }^{31}$ This is formally derived in Proposition 1 below.
} 


\section{Figure 2: Optimal non interest-bearing CBDC design}

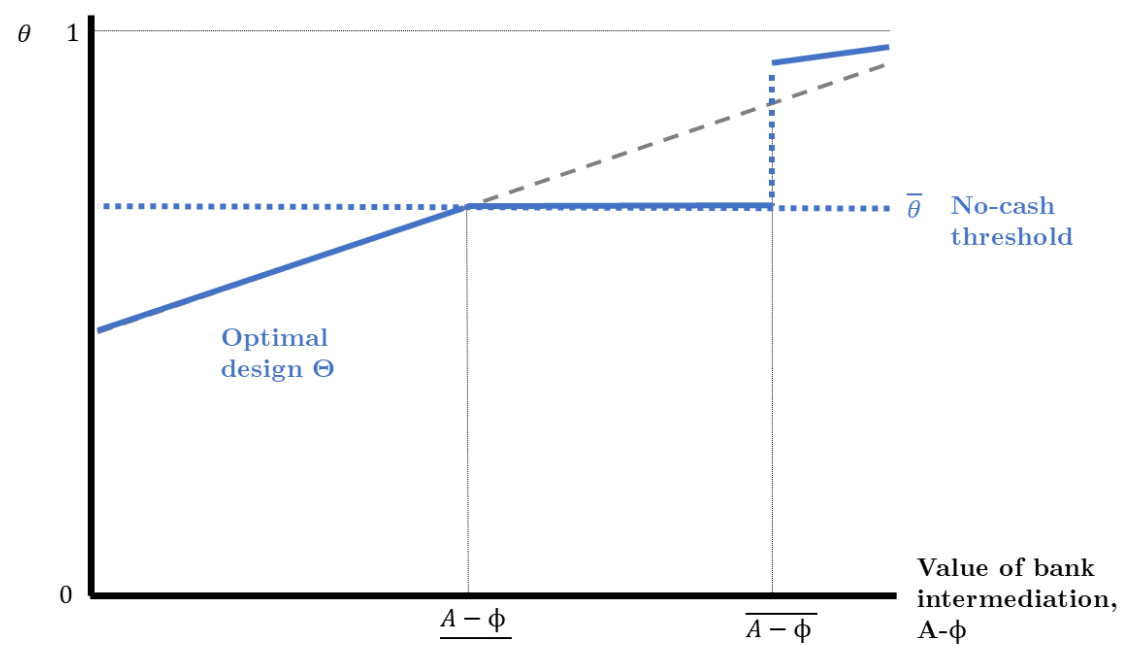

Figure 2 brings together several key aspects of our model. ${ }^{32}$ First, when network effects do not constrain policy, the optimal similarity of the CBDC to cash depends on the extent to which banks have an advantage at alleviating financial frictions. On the one hand, locating the CBDC "centrally" relative to the attraction points of deposits and cash serves the payments needs of households with diverse preferences. On the other hand, when bank intermediation has more value, the CBDC is optimally made more cash-like, so as to limit its adverse impact on banks' deposit base, and thereby aggregate output and consumption.

Second, as the value of bank intermediation $(A-\phi)$ rises, a threshold $A-\phi$ is eventually reached, beyond which optimal design freezes in relation to $(A-\phi)$. This is because optimal policy prevents the disappearance of cash in order to protect payment instrument variety. As long as the welfare gains from payment instrument variety outweigh the welfare costs from lost bank intermediation, optimal policy maintains all three payment instruments, rather than tipping cash over the disappearance point induced by network effects. However, when preserving bank intermediation becomes the dominant concern (namely when $A-\phi$ exceeds the threshold $\overline{A-\phi}$ ), optimal policy foregoes on variety, allowing for the disappearance of cash, in exchange for a larger deposit base for banks.

Third, once cash vanishes, the CBDC bears the brunt of servicing former cash users, and therefore optimally moves further towards cash than it would have if all three forms of money were still in existence. In Figure 2, this is seen from the portion of the blue line to the right of $\overline{A-\phi}$, which is above the dashed gray line.

This last portion of the blue line also demonstrates the outcome when fundamentals are such that

\footnotetext{
${ }^{32}$ In addition to optimal policy derived in the Proof of Proposition 1, the exact shape of Figure 2 relies on two more properties from (36) and (37): first, $\theta^{\text {nce }}>\theta^{c e}$; second, $\frac{\partial \theta^{c e}}{\partial(A-\phi)}<\frac{\partial \theta^{\text {nce }}}{\partial(A-\phi)}<0$ and therefore the slope of $\theta^{\text {nce }}$ is flatter.
} 
cash disappears prior to the introduction of a CBDC. If the CBDC is introduced after cash has disappeared, optimal policy is simply depicted by extending the portion of the blue line to right of $\overline{A-\phi}$ all the way to the vertical axis. In this case, network effects no longer play a role since cash would already be out of use. As such, in a country that starts off cashless, optimal CBDC policy is quite straightforward, and the CBDC is always more cash-like than when cash exists.

\subsection{Interest-bearing CBDC}

This section considers an interest-bearing CBDC, where the CBDC rate can be varied as desired to maximize welfare. Unconstrained optimal policy is now given by the solution to the system of two first order conditions, $\left\{\frac{\partial W\left(\theta, r_{c b d c}\right)}{\partial \theta}=0, \frac{\partial W\left(\theta, r_{c b d c}\right)}{\partial r_{c b d c}}=0\right\}$, which yields the same expressions for $\theta^{c e}$ and $\theta^{\text {nce }}$ as in (36) and (37) and for CBDC rates

$$
r_{c b d c}^{c e}=r_{c b d c}^{n c e}=0
$$

with the implication that the optimal CBDC rate is always zero in the absence of network effects. This outcome is consistent with the discussion in Section 2.2.2, which suggest that the CBDC interest rate is a suboptimal tool compared to $\theta$. As such, our model indicates that in a world without network effects, central banks would be right to focus their attention on the issuance of non interest-bearing CBDCs. ${ }^{33}$

However, as discussed in Section 3.1, such an optimal policy profile is not always implementable, due to network effects. For an interest-bearing CBDC, the equilibrium determination condition (28) affects both $\theta$ and $r_{c b d c}$. When this condition binds, and the central bank chooses to satisfy it in order to preserve cash, optimal CBDC design becomes

$$
\begin{aligned}
\tilde{\theta} & =\frac{2+\rho(2(A-\phi)-1-\rho(4+\rho)(2 \underline{s}-1))}{4+\rho(1+\rho)(3+\rho)} \\
\widetilde{r}_{c b d c} & =-2 \frac{\rho((A-\phi)+3 \underline{s}-2)+4 \underline{s}-1}{4+\rho(1+\rho)(3+\rho)}
\end{aligned}
$$

Hence, when network effects come into play, the optimal CBDC rate diverges from zero. Indeed, under the parameter restrictions in (17), the optimal CBDC rate always turns negative. This in turn allows CBDC design to become more cash-like compared to the non-interest bearing case $(\widetilde{\theta}>\bar{\theta})$ as the value of bank intermediation $(A-\phi)$ rises.

Note that the constrained non interest-bearing optimal policy $\left(\theta, r_{c b d c}\right)=(\bar{\theta}, 0)$ is within the feasible set of policies delineated by (28), but is found to be sub-optimal. Therefore, access to a second policy tool in the CBDC interest rate strictly raises welfare when network effects bind. Proposition 1 records our key results on optimal CBDC design, which are depicted in Figure 3.

\footnotetext{
${ }^{33}$ Appendix $\mathrm{C}$ investigates the robustness of this key result. We find that the optimality of zero CBDC rates (absent network effects) is robust to the specification of the production function. However, when banks have market power (Appendix C.3), or when anonymous payments instruments create negative social externalities (Appendix C.2), the optimal CBDC rate can deviate from zero.
} 


\section{Figure 3: Optimal interest-bearing CBDC design}

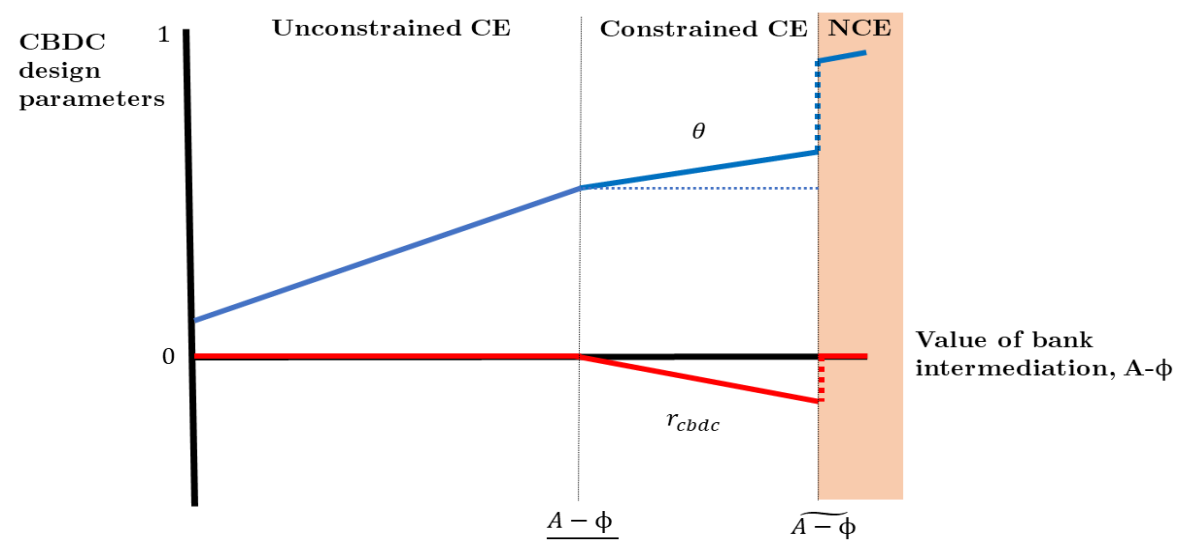

Proposition 1 There is a cutoff $\bar{\rho} \in\left(\frac{3}{4}, \frac{3}{2}\right)$, such that when $\rho<\bar{\rho}$, cash never vanishes under an optimally designed interest-bearing $C B D C$, where optimal design is given by

$$
\left\{\begin{array}{c}
\left(\widetilde{\theta}, \widetilde{r}_{c b d c}\right) \text { if } \theta^{c e}+\rho r_{c b d c}^{c e}<1-2 \underline{s} \\
\left(\theta^{c e}, r_{c b d c}^{c e}\right) \text { otherwise }
\end{array}\right.
$$

For $\rho>\bar{\rho}$, cash can vanish when the value to bank intermediation exceeds a threshold $\widetilde{A-\phi}$. However, this threshold is higher when the CBDC is interest-bearing than when it is not, that is, $\widetilde{A-\phi}>\overline{A-\phi}$

\section{Proof. Provided in Appendix A.}

When the relative weight of payments preferences in household utility is large enough $(\rho<\bar{\rho})$, the presence of a variable CBDC interest rate as a second tool fundamentally alters the outcomes under optimal policy, as compared to a non interest-bearing CBDC, depicted in Figure 2. With a non interest-bearing CBDC, the only means to safeguard deposits is to make the CBDC eat into cash demand. But with a variable CBDC interest rate, optimal policy simultaneously reaps the welfare benefits of sustaining variety in payment instruments and limits bank disintermediation. In particular, when network effects bind, optimal policy combines a (more) cash-like CBDC with a negative CBDC interest rate, thereby circumnavigating adverse network effects on cash use by making the CBDC less attractive, while simultaneously limiting the CBDC's impact on financial intermediation and production. This optimal policy is portrayed in the unshaded part of Figure 3. For $\rho<\bar{\rho}$, the shaded part of this figure is never reached, which means that cash never vanishes under optimal policy.

However, the deeper the CBDC interest rate moves into negative territory, the larger its costs in terms of payment choice distortions become. If the weight on payments preferences is relatively small $(\rho>\bar{\rho})$, then a point is reached where the value of bank intermediation $(A-\phi)$ is large enough that welfare is best served by letting go of cash. This case, portrayed by the shaded area 
Figure 4: Distributional effects of CBDC

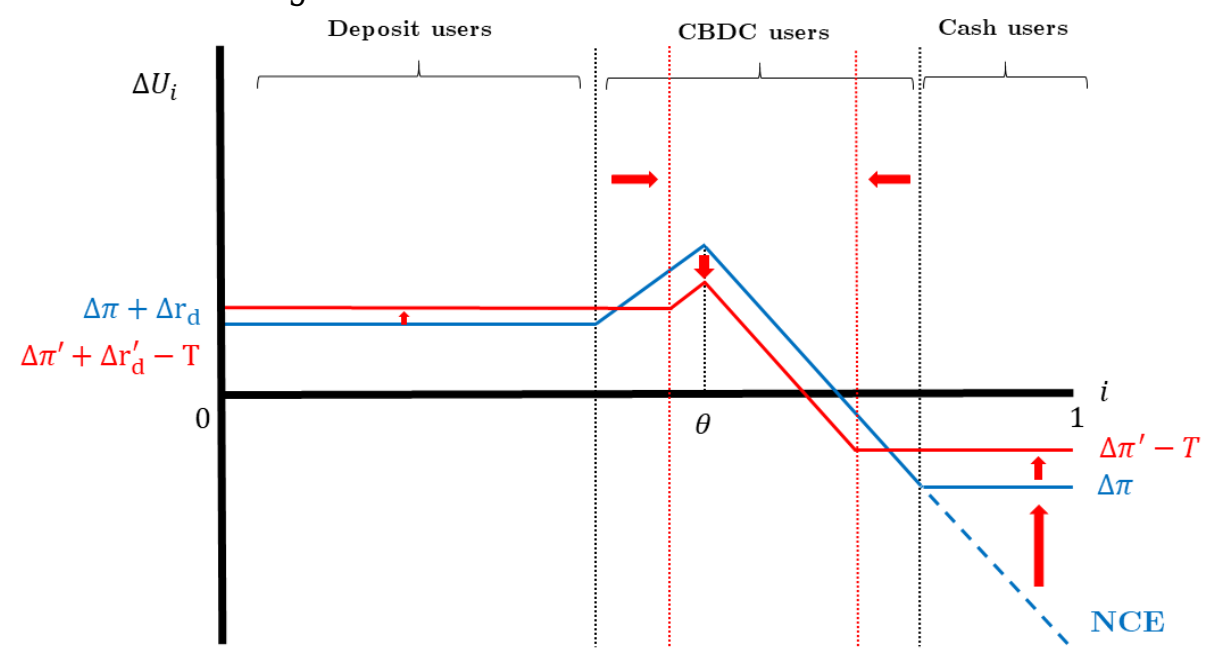

Note: See Appendix B for the underlying derivations.

in Figure 3, is similar to the jump seen in Figure 2: optimal policy switches to $\left(\theta^{n c e}, r_{c b d c}^{n c e}\right)$, which implies a more cash-like CBDC to better accommodate the preferences of previous cash users, and a return to zero CBDC rates. Nevertheless, even when $\rho>\bar{\rho}$, the availability of CBDC interest rates serves a purpose. In particular, raising $(A-\phi)$ from lower to higher values, the possibility of varying the CBDC interest rates "delays" the jump to a cashless equilibrium where households lose access to three differentiated means of payment (i.e., $\widetilde{A-\phi}>\overline{A-\phi}$ )

\subsection{Distributional effects}

So far, our welfare analysis has centered on aggregate welfare, which represents the total utility of all households. Introducing an optimally designed CBDC always raises aggregate welfare in our framework, but this is far from a Pareto improvement: some households gain while others lose. Figure 4 shows the welfare impact of introducing a CBDC across the distribution of household preferences $i \in[0,1] \cdot{ }^{34}$ The blue line depicts the impact of a non interest-bearing CBDC.

To begin with, households with payment preferences closest to deposits (i.e., low $i$ ) remain as deposit users after the introduction of a CBDC. These households are impacted by the introduction of a CBDC through its negative effects on financial intermediation, as well as its positive effects on bank deposit rates. On the one hand, the decline in financial intermediation reduces total production and therefore profit transfers, $\pi$, from firms. On the other hand, CBDC competition with bank deposits drives up deposit rates, $r_{d}$. Overall, the latter effect dominates and the introduction of a CBDC raises the consumption, and hence the welfare, of all deposit users.

At the other end of the spectrum, households with a strong preference for anonymity (i.e., high i) remain as cash users. CBDC impacts the welfare of these households through consumption.

\footnotetext{
${ }^{34}$ See Appendix B for the underlying derivations.
} 
Since cash does not pay interest, the decline in firm profits $\pi$ brings about a decline in consumption and welfare for these households. If instead the CBDC instigates network effects on cash and drives it out of use, these households suffer from a further decline in welfare due to the loss of their preferred payments instrument. The extent of their welfare loss then becomes proportionate to their preference for anonymity, as depicted by the dashed blue line.

Households that switch from deposits to CBDC, experience a net welfare gain from CBDC introduction, since otherwise they would have continued to use deposits. In other words, by virtue of optimality, these households only switch to CBDC if the gains in terms of payment preferences outweighs the loss of interest payments $r_{d}$. The household with preference $i=\theta$ experiences the greatest increase in welfare. For households that marginally prefer CBDC over cash, the net welfare effect is negative, since CBDC holders also suffer from a fall in consumption due to reduced firm profits.

Overall, we can define a boundary household, $\bar{i}$, such that households $i \in[0, \bar{i})$ gain from the introduction of a CBDC and households $i \in(\bar{i}, 1]$ lose, where the gains of the former group more than offset the losses of latter in aggregate. The fact that depositors emerge as winners and cash holders as losers, hints at a potentially regressive impact of a CBDC. In our analysis, all households have identical endowments. In practice, however, households that primarily conduct their payments with cash tend to have lower income, while higher income households more often rely on deposit-based payments.

The red line in Figure 4 shows the welfare impact of an interest-bearing CBDC with slightly negative CBDC rates as per the optimal design prescribed in Section 3.2. Three factors determine the impact of negative CBDC rates here. First, the revenues from negative CBDC rates are transferred lump-sum to all households, which effectively redistributes welfare gains from CBDC users to cash and deposit users. Second, since negative CBDC rates increase deposits and financial intermediation, firm profits $\pi$ rise, which benefits all households, while deposit rates $r_{d}$ decrease, hurting depositors. However, the second effect is dominated by the first, in that overall CBDC users lose out and deposit and cash users gain from the CBDC rate cut. Third, when CBDC rates prevent cash from going out of use, they stave off large welfare losses for cash holders from the loss of a preferred payments instrument.

\section{Conclusion}

As central banks across the world weigh the introduction of a digital currency, the implications of a CBDC for money demand and financial intermediation are coming to the fore. This paper relates the effects on cash, deposits and bank intermediation to two key design choices involved in developing a CBDC: the degree to which the CBDC resembles cash, and whether it is interestbearing. In our framework, the social value of the CBDC comes from the fact that it can bring some of the anonymity of cash into the digital realm. The demand for digital payments privacy is already a major issue in some jurisdictions, and is likely to gain increased prominence globally with the spread of fintech and companies' ability to parse large transactions data for their own gain. 
CBDCs currently under consideration are mostly of a non interest-bearing type. Analyzing the optimal design of a non interest-bearing CBDC lays bare a challenging welfare tradeoff for the central bank. On the one hand, a cash-like CBDC risks reducing cash demand below the critical mass where ATMs become sparser and fewer shops accept cash, placing at risk the variety of payment instruments that is valuable to households with diverse needs. On the other hand, if the central bank makes a CBDC more similar to deposits, banks' deposit base can come under threat, with negative implications for credit provision and output, especially if banks have a significant role in alleviating lending frictions.

Overall, in an economy where banks' role is limited, a CBDC is best designed in a manner that is as distinct from existing payment instruments as possible. Greater focus on preserving bank intermediation instead drives optimal CBDC design to be more cash-like, but only up to a point: concerns that cash may fall prey to network effects gives the central bank cause to limit the extent to which CBDC competes against cash. Only when conserving banks' deposit base becomes the overarching concern does the central bank give up on cash, and optimal policy then jumps towards a more cash-like CBDC.

When network effects matter, an interest-bearing CBDC helps the central bank alleviate these tradeoffs. Moving the CBDC interest rate away from zero causes welfare losses as it creates price distortions in households' choice over payment instruments. As long as network effects do not hold sway, the central bank thus shies away from varying the CBDC interest rate. Therefore, in a world where network effects have no material impact, nothing is lost by limiting CBDC design to non interest-bearing CBDCs. However, when network effects pose a threat to the variety of payment instruments, an interest bearing CBDC becomes optimal. Notably, provided households care enough about payments variety, the CBDC interest rate can be used to ensure that cash remains in use. That is, an optimally designed interest-bearing CBDC hits the aims of safeguarding bank intermediation and protecting the trio of payment instruments against network effects, irrespective of the role of financial frictions in the economy.

This finding provides an economic counterweight to the political economy considerations that may otherwise drive central banks to opt for a non interest-bearing CBDC, such as concerns about the possibility of negative rates on publicly accessible central bank liabilities. At this early stage, when CBDCs are still in the laboratory, central banks may want to at least keep an eye on the inclusion of an adjustable CBDC interest rate, weighing its benefits against possible political economy costs. 


\section{References}

Agarwal, R. and Kimball, M. (2015). Breaking Through the Zero Lower Bound. IMF Working Papers 15/224, International Monetary Fund.

Agarwal, R. and Kimball, M. (2019). Enabling Deep Negative Rates to Fight Recessions: A Guide. IMF Working Papers 19/84, International Monetary Fund.

Andolfatto, D. (2018). Assessing the Impact of Central Bank Digital Currency on Private Banks. Working Papers 2018-25, Federal Reserve Bank of St. Louis.

Assenmacher, K. and Krogstrup, S. (2018). Monetary Policy with Negative Interest Rates: Decoupling Cash from Electronic Money. IMF Working Papers 18/191, International Monetary Fund.

Athey, S., Catalini, C., and Tucker, C. (2017). The Digital Privacy Paradox: Small Money, Small Costs, Small Talk. NBER Working Papers 23488, National Bureau of Economic Research.

Bank for International Settlements (2018). Central Bank Digital Currencies. Technical report, Basel Committee on Payments and Market Infrastructures.

Barontini, C. and Holden, H. (2019). Proceeding with Caution - a Survey on Central Bank Digital Currency. BIS Papers 101, Bank for International Settlements.

Barrdear, J. and Kumhof, M. (2016). The Macroeconomics of Central Bank Issued Digital Currencies. Bank of England working papers 605, Bank of England.

Bech, M. L. and Garratt, R. (2017). Central Bank Cryptocurrencies. BIS Quarterly Review.

Bergara, M. and Ponce, J. (2018). Central Bank Digital Currencies: the Uruguayan e-Peso Case. In Masciandaro, D. and Gnan, E., editors, Do We Need Central Bank Digital Currency? Economics, Technology and Institutions. SUERF Conference Volume.

Biais, B., Bisière, C., Bouvard, M., and Casamatta, C. (2019). The Blockchain Folk Theorem. Review of Financial Studies, 32(5):1662-1715.

Biais, B., Bisière, C., Bouvard, M., Casamatta, C., and Menkveld, A. J. (2018). Equilibrium Bitcoin Pricing. TSE Working Papers 18-973, Toulouse School of Economics (TSE).

Bjerg, O. (2017). Designing New Money - The Policy Trilemma of Central Bank Digital Currency. CBS Working Paper, June 2017.

Bolt, W. and Van Oordt, M. R. (2019). On the Value of Virtual Currencies. Journal of Money, Credit and Banking, forthcoming.

Bordo, M. D. and Levin, A. T. (2017). Central Bank Digital Currency and the Future of Monetary Policy. NBER Working Papers 23711, National Bureau of Economic Research. 
Borgonovo, E., Caselli, S., Cillo, A., and Masciandaro, D. (2018). Between Cash, Deposit And Bitcoin: Would We Like A Central Bank Digital Currency? Money Demand And Experimental Economics. BAFFI CAREFIN Working Papers 1875.

Bounie, D., François, A., and Van Hove, L. (2017). Consumer Payment Preferences, Network Externalities, and Merchant Card Acceptance: An Empirical Investigation. Review of Industrial Organization, 51(3):257-290.

Brunnermeier, M. K. and Niepelt, D. (2019). On the Equivalence of Private and Public Money. NBER Working Papers 25877, National Bureau of Economic Research.

Chakravorti, S. (2010). Externalities in Payment Card Networks: Theory and Evidence. Review of Network Economics, 9(2):1-28.

Chiu, J., Davoodalhosseini, M., Jiang, J. H., and Zhu, Y. (2019). Central Bank Digital Currency and Banking. Staff Working Papers 19-20, Bank of Canada.

Chodorow-Reich, G., Gopinath, G., Mishra, P., and Narayanan, A. (2018). Cash and the Economy: Evidence from India's Demonetization. NBER Working Papers 25370, National Bureau of Economic Research.

Davoodalhosseini, M. (2018). Central Bank Digital Currency and Monetary Policy. Staff Working Papers 18-36, Bank of Canada.

Diamond, D. W. and Rajan, R. G. (2001). Liquidity Risk, Liquidity Creation, and Financial Fragility: A Theory of Banking. Journal of Political Economy, 109(2):287-327.

Donaldson, J. R., Piacentino, G., and Thakor, A. (2018). Warehouse Banking. Journal of Financial Economics, 129(2):250 - 267.

Engert, W. and Fung, B. (2017). Central Bank Digital Currency: Motivations and Implications. Discussion Papers 17-16, Bank of Canada.

Engert, W., Fung, B., and Hendry, S. (2018). Is a Cashless Society Problematic? Discussion Papers 18-12, Bank of Canada.

Fung, B. and Halaburda, H. (2016). Central Bank Digital Currencies: A Framework for Assessing Why and How. Discussion Papers 16-22, Bank of Canada.

Garratt, R. and van Oordt, M. (2019). Privacy as a Public Good: A Case for Electronic Cash. Staff Working Papers 19-24, Bank of Canada.

Goodfriend, M. (2016). The Case for Unencumbering Interest Rate Policy at the Zero Lower Bound. Paper presented at the August 2016, Jackson Hole Conference.

Gopinath, G. and Stein, J. C. (2018). Banking, Trade, and the Making of a Dominant Currency. Working Paper 24485, National Bureau of Economic Research. 
He, D., Leckow, R. B., Haksar, V., Mancini-Griffoli, T., Jenkinson, N., Kashima, M., Khiaonarong, T., Rochon, C., and Tourpe, H. (2017). Fintech and Financial Services; Initial Considerations. IMF Staff Discussion Notes 17/05, International Monetary Fund.

Kahn, C. M., Rivadeneyra, F., and Wong, T.-N. (2019). Should the Central Bank Issue E-Money? Working Papers 2019-3, Federal Reserve Bank of St. Louis.

Katz, M. L. and Shapiro, C. (1985). Network Externalities, Competition, and Compatibility. The American Economic Review, 75(3):424-440.

Keister, T. and Sanches, D. R. (2019). Should Central Banks Issue Digital Currency? Working Papers 19-26, Federal Reserve Bank of Philadelphia.

Kim, Y. S. and Kwon, O. (2019). Central Bank Digital Currency and Financial Stability. Working Papers 2019-6, Economic Research Institute, Bank of Korea.

Krugman, P. (1979). Increasing Returns, Monopolistic Competition, and International Trade. Journal of International Economics, 9(4):469-479.

Lagarde, C. (2018). Winds of Change: The Case for a New Digital Currency. Remarks at the Singapore Fintech Festival.

Mancini-Griffoli, T., Martinez Peria, M. S., Agur, I., Ari, A., Kiff, J., Popescu, A., and Rochon, C. (2018). Casting Light on Central Bank Digital Currencies. IMF Staff Discussion Notes 18/08, International Monetary Fund.

Masciandaro, D. (2018). The Demand for a Central Bank Digital Currency: Liquidity, Return and Anonymity. In Masciandaro, D. and Gnan, E., editors, Do We Need Central Bank Digital Currency? Economics, Technology and Institutions. SUERF Conference Volume.

McAndrews, J. (2017). The Case for Cash. ADBI Working Papers 679, Asian Development Bank Institute.

Meaning, J., Dyson, B., Barker, J., and Clayton, E. (2018). Broadening Narrow Money: Monetary Policy with a Central Bank Digital Currency. Bank of England working papers 724, Bank of England.

Merrouche, O. and Nier, E. (2012). Payment Systems, Inside Money and Financial Intermediation. Journal of Financial Intermediation, 21(3):359-382.

Miccoli, M. (2019). Central Bank Digital Currencies, Bank Runs and Welfare. mimeo.

Niepelt, D. (2019). Reserves for All? Central Bank Digital Currency, Deposits, and their (Non)Equivalence. International Journal of Central Banking, forthcoming.

Norges Bank (2018). Central Bank Digital Currencies. Norges Bank Papers No 1/2018.

Prasad, E. (2018). Central Banking in the Digital Age: Stock-Taking and Preliminary Thoughts. Discussion paper, Hutchins Center on Fiscal and Monetary Policy at Brookings. 
Rochet, J.-C. and Tirole, J. (2006). Externalities and Regulation in Card Payment Systems. Review of Network Economics, 5(1):1-14.

Rogoff, K. (2016). The Curse of Cash. Princeton University Press, 1st edition.

Stein, J. C. (2012). Monetary Policy as Financial Stability Regulation. The Quarterly Journal of Economics, 127(1):57.

Sveriges Riksbank (2017). Central Bank Digital Currencies. Technical report, 1st interim report on the e-krona project.

Sveriges Riksbank (2018a). Special Issue on the e-Krona. Technical report, Sveriges Riksbank Economic Review.

Sveriges Riksbank (2018b). The Riksbank's E-Krona Project. Technical report, Report 2.

Wakamori, N. and Welte, A. (2017). Why Do Shoppers Use Cash? Evidence from Shopping Diary Data. Journal of Money, Credit and Banking, 49(1):115-169.

Wright, R., Tekin, E., Topalli, V., McClellan, C., Dickinson, T., and Rosenfeld, R. (2017). Less Cash, Less Crime: Evidence from the Electronic Benefit Transfer Program. Journal of Law and Economics, 60(2):361-383.

Yao, Q. (2018). A Systematic Framework to Understand Central Bank Digital Currency. Science China Information Sciences, 61(3):033101. 


\section{Appendix}

\section{A Proofs}

Proof of Lemma 1. A CBDC can be designed in a manner that mimics cash: $\left(\theta, r_{c b d c}\right)=(1,0)$. From this, it directly follows that welfare in both ce and nce is higher than in an equilibrium without CBDC: in both $c e$ and nce the central bank could attain the same welfare as in the equilibrium without CBDC, by setting $\theta=1$ and $r_{c b d c}=0$, but this policy combination is never optimal, as seen from (36) and (37) where $\theta^{c e}<\theta^{n c e}<1$. Hence, $W(1,0)<W\left(\theta^{n c e}, r_{c b d c}^{n c e}\right)<$ $W\left(\theta^{c e}, r_{c b d c}^{c e}\right)$, where the last inequality follows from (38).

Proof of Lemma 2. Replacing from (36), (40) and (23) into (18)-(20) gives the expressions for the shares of money, $s_{c}^{c e}, s_{d}^{c e}$, and $s_{c b d c}^{c e}$, when all forms of money exist (ce), in terms of parameters only. We can then calculate the infima of $s_{c}^{c e}, s_{d}^{c e}$, and $s_{c b d c}^{c e}$ respectively, over the parameter space defined by (17). This yields

$$
\begin{aligned}
\inf s_{c}^{c e} & =\frac{1}{34} \\
\inf s_{d}^{c e} & =\frac{2}{17} \\
\inf s_{c b d c}^{c e} & =\frac{1}{17}
\end{aligned}
$$

and therefore, given $\underline{s} \leq \frac{1}{17}$ in (17), it follows that $\eta_{d}=\eta_{c b d c}=0 .{ }^{35}$

Moreover, using (36) and (40), as well as (23), we can also verify that two necessary conditions for positive CBDC take up, which are subsumed by the CBDC design constraint (15), are also satisfied. These conditions are

$$
\begin{aligned}
r_{c b d c} & \geq-(1-\theta) \rho^{-1} \\
\theta & >\rho\left(r_{d}-r_{c b d c}\right)
\end{aligned}
$$

which respectively rule out the strict dominance of CBDC by cash and deposits (i.e., ensure that neither cash nor deposits offer all households a strictly better utility than CBDC) as per (5) and (7). First, since $\sup \theta^{c e}=\frac{16}{17}<\sup \theta^{\text {nce }}=\frac{23}{24}<1$, while $r_{c b d c}=0$, condition (44) cannot be violated. Second, as $\inf \left(\theta^{c e}-\rho r_{d}\right)=\frac{1}{17}$ over the parameter space in (17), (45) is never violated either (and this necessarily also holds for $\theta^{\text {nce }}$, since $\theta^{\text {nce }}>\theta^{c e}$ ).

\footnotetext{
${ }^{35}$ This also remains valid in $n c e$ where inf $s_{d}^{c e}=\frac{1}{6}$ and inf $s_{c b d c}^{c e}=\frac{1}{12}$.
} 
Proof of Lemma 3. $W^{c e}\left(\theta, r_{c b d c}\right)$ can be determined by solving the following system of 11 equations in 11 unknowns, which gives the expression (30):

$$
\begin{aligned}
W & =\rho\left(1+\phi k_{0}+\left(A-1-\phi-\frac{s_{d}}{2}\right) s_{d}\right)-s_{d} E_{d}-s_{c b d c 1} E_{c b d c 1}-s_{c b d c 2} E_{c b d c 2}-s_{c} E_{c} \\
s_{d} & =\frac{\theta+\rho\left(r_{d}-r_{c b d c}\right)}{2} \\
s_{c b d c} & =s_{c b d c 1}+s_{c b d c 2} \\
s_{c b d c 1} & =\frac{\theta-\rho\left(r_{d}-r_{c b d c}\right)}{2} \\
s_{c b d c 2} & =\frac{1+\rho r_{c b d c}-\theta}{2} \\
s_{c} & =\frac{1-\theta-\rho r_{c b d c}}{2} \\
E_{d} & =\left|0-\frac{1}{2} s_{d}\right|=\frac{s_{d}}{2} \\
E_{c b d c 1} & =\left|\theta-\left(s_{d}+\frac{1}{2} s_{c b d c 1}\right)\right|=\left(\theta-s_{d}-\frac{1}{2} s_{c b d c 1}\right) \\
E_{c b d c 2} & =\left|\theta-\left(s_{d}+s_{c b d c 1}+\frac{1}{2} s_{c b d c 2}\right)\right|=s_{d}+s_{c b d c 1}+\frac{1}{2} s_{c b d c 2}-\theta \\
E_{c} & =\left|1-\left(1-\frac{1}{2} s_{c}\right)\right|=\frac{1}{2} s_{c} \\
r_{d} & =\frac{2(A-1-\phi)+\rho r_{c b d c}-\theta}{2+\rho}
\end{aligned}
$$

Similarly, the solution for $W^{n c e}\left(\theta, r_{c b d c}\right)$ is found by setting $s_{c}=0$ in the above, and solving. This yields the expression in (31).

Proof of Proposition 1. First, we note that $W^{c e}\left(\theta^{c e}, r_{c b d c}^{c e}\right)>W^{\text {nce }}\left(\theta^{\text {nce }}, r_{c b d c}^{\text {nce }}\right)$, per (38). Moreover, $W^{c e}\left(\theta^{c e}, r_{c b d c}^{c e}\right)>W^{c e}\left(\widetilde{\theta}, \widetilde{r}_{c b d c}\right)$ per definition, as welfare under unconstrained optimal policies exceeds welfare under constrained optimal policies within a given equilibrium (namely, $c e$ ). Hence, as long as the unconstrained $c e$ is feasible, it is optimal. Therefore, the relevant comparison centers on $W^{n c e}\left(\theta^{n c e}, r_{c b d c}^{n c e}\right)$ versus $W^{c e}\left(\widetilde{\theta}, \widetilde{r}_{c b d c}\right)$ when the network effects constraint matters, that is, when $\theta^{c e}+r_{c b d c}^{c e}=\theta^{c e}>1-2 \underline{s}$.

Second,

$$
\inf _{A, \phi, \underline{s}}\left[W^{n c e}\left(\theta^{n c e}, r_{c b d c}^{n c e}\right)-W^{c e}\left(\widetilde{\theta}, \widetilde{r}_{c b d c}\right)\right]>0 \Leftrightarrow \rho>1.431=\bar{\rho}
$$

which means that for $\rho<\bar{\rho}$, the policy combination $\left(\widetilde{\theta}, \widetilde{r}_{c b d c}\right)$ always (i.e., for any values of other parameters) welfare dominates $\left(\theta^{n c e}, r_{c b d c}^{n c e}\right)$, and hence cash never vanishes under optimal policies. Instead, for $\rho>\bar{\rho}$, there exist parameterizations, including the extremes of $(A-\phi)=\frac{5}{2}$ and $\underline{s}=\frac{1}{17}$, such that $\left(\theta^{n c e}, r_{c b d c}^{n c e}\right)$ welfare dominates $\left(\widetilde{\theta}, \widetilde{r}_{c b d c}\right)$. That is, when $\rho>\bar{\rho}$, cash can optimally be allowed to vanish, when network effects are strong enough $(\underline{s})$ and the value of bank 
intermediation $(A-\phi)$ is large enough.

Third, whenever $\theta^{c e}>\bar{\theta}=1-2 \underline{s}$, it is necessarily true that

$$
W^{c e}\left(\widetilde{\theta}, \widetilde{r}_{c b d c}\right)-W^{c e}(\bar{\theta}, 0)>0
$$

since $\left(\widetilde{\theta}, \widetilde{r}_{c b d c}\right)=(\bar{\theta}, 0)$ is within the possibility set of $\left(\widetilde{\theta}, \widetilde{r}_{c b d c}\right)$ but is not optimally chosen, as seen from (41) and (42). Hence, the range of parameter values where $W^{c e}\left(\widetilde{\theta}, \widetilde{r}_{c b d c}\right)>$ $W^{\text {nce }}\left(\theta^{\text {nce }}, r_{c b d c}^{n c e}\right)$ is broader than the range where $W^{c e}(\bar{\theta}, 0)>W^{\text {nce }}\left(\theta^{n c e}, r_{c b d c}^{n c e}\right)$. To put this in more concrete terms, consider $\rho>\bar{\rho}$ and $\underline{s}=\frac{1}{17}$. Then, the value of $(A-\phi)$ that is large enough to induce a switch from ce to nce is higher when policies are set at $\left(\widetilde{\theta}, \widetilde{r}_{c b d c}\right)$ than when they are set at $(\bar{\theta}, 0)$.

\section{B Derivation of distributional effects}

The foundations for Figure 4 are found by considering the impact of a CBDC on, respectively, deposit, cash and CBDC users. We use the term "after the introduction of a CBDC" to indicate the comparison between a world with cash and deposits only, and one where CBDC is available as an additional payments instrument.

\section{B.1 Depositors}

For a household that continues using deposits after the introduction of a CBDC, such as $i=0$, nothing changes in terms of the payment preference aspect of utility through the introduction of a CBDC. Hence, her tradeoff centers on consumption, as represented by

$$
\begin{aligned}
C_{d} & =1+r_{d}+\pi-T \\
& =1+r_{d}\left(1-s_{d}\right)+\phi k_{0}+\left(A-1-\phi-\frac{s_{d}}{2}\right) s_{d}-r_{c b d c} s_{c b d c}
\end{aligned}
$$

where $T=r_{c b d c} s_{c b d c}$ and $\pi$ has been replaced using (10), (11), and (16). Further replacing for $s_{d}$, $s_{c b d c}$, and $r_{d}$ with expressions as shown in the proof of Lemma 3 , this gives a closed-form expression for $C_{d}$. From this expression, we obtain

$$
\left.\frac{\partial C_{d}}{\partial \theta}\right|_{r_{c b d c}=0}=\frac{\rho(A-\phi-2)+\theta-2}{(2+\rho)^{2}}<0
$$

which means that the introduction of a non interest-bearing CBDC always raises welfare for households that continue using deposits, because the introduction of a CBDC is equivalent to 
lowering $\theta$ from $\theta=1$ (cash equivalence) to a lower value. ${ }^{36}$ Put differently, the more intensely the CBDC competes with bank deposits (lower $\theta$ ) the more it pushes up deposit rates, and the larger the welfare gains to depositors.

Moreover,

$$
\frac{\partial C_{d}}{\partial r_{c b d c}}=\frac{-4-\rho\left(4(A-\phi-1)-\rho+2 r_{c d b c}(8+\rho(5+\rho))+\theta(4+\rho)\right)}{2(2+\rho)^{2}}
$$

where we find that at $r_{c d b c}=0$, this term is negative overall, given the parameter space in (17) and $\theta \leq 1$. Hence, a marginal CBDC interest rate cut from $r_{c d b c}=0$ to $r_{c d b c}<0$ always raises the welfare of depositors.

\section{B.2 Cash holders}

For a household that continues using cash after the introduction of a CBDC (provided cash remains in use), such as $i=1$, welfare effects similarly center on consumption only, as her payments instrument preferences are unaffected. Contrary to depositors, however, the impact of a non interest-bearing CBDC on cash holders is straightforward: While depositors see gains from increased deposit rates that (more than) compensate for lost firm profit transfers, cash holders see only those lost profit transfers, and are therefore necessarily worse off: $\left.\frac{\partial C_{c}}{\partial \theta}\right|_{r_{c b d c}=0}>0$. Those cash holders would be even worse off if network effects push cash out of use and they are forced to take solace in a CBDC that is more distant from their payment preferences.

The impact of negative CBDC rates is also straightforward for cash holders. As cash pays no interest, the only channels through which cash holders are affected are $\pi$, which rises as the CBDC rate declines (increased financial intermediation), and $T$, which is positive when CBDC interest rates are negative (CBDC holders are taxed, and the proceeds accrue to all households). That is, $\frac{\partial C_{c}}{\partial r_{c b d c}}<0$, as shown in Figure 4.

\section{B.3 CBDC users}

For households that switch to CBDC after it has been introduced, the key question is whether their gains in payment preferences outweigh lost consumption arising from bank disintermediation. Former depositors switching to CBDC, always see a welfare improvement overall. If they did not, they would have remained depositors, since depositors see welfare gains from the introduction of a CBDC, as per (50). The $i=\theta$ household experiences the largest welfare gain from the availability of a CBDC, because the CBDC precisely meets her payments preferences.

\footnotetext{
${ }^{36}$ Formally, we can verify that $\left.\frac{\partial C_{d}}{\partial \theta}\right|_{r_{c b d c}=0}<0$ by noting that in (50) when $A-\phi \rightarrow 1$ the expression becomes $\frac{\theta-\rho-2}{(2+\rho)^{2}}$ and when $A-\phi \rightarrow \frac{5}{2}$ it becomes $\frac{\frac{1}{2} \rho+\theta-2}{(2+\rho)^{2}}$, both of which are smaller than 0 given $\rho \leq \frac{3}{2}$ and $\theta \leq 1$. Hence, $\left.\frac{\partial C_{d}}{\partial \theta}\right|_{r_{c b d c}=0}<0$ always holds over the parameter space in (17).
} 
However, some of the $i>\theta$ CBDC holders would have been better off had CBDC not existed. After all, the household that is exactly indifferent between holding cash and holding CBDC experiences a welfare loss, since all cash holders lose welfare, and this household is indifferent between the welfare loss of continuing to hold cash, and the welfare loss from holding CBDC. CBDC holders with $i$ marginally below this indifferent household would also certainly see an overall welfare loss. CBDC does not offer them enough of an attractive payment option to compensate for the loss in firm profit transfers. Finally, a negative CBDC rate acts as a tax on CBDC holders, and therefore reduces their welfare, as shown in Figure 4.

\section{Extensions}

\section{C.1 Constant returns to scale production function}

The baseline model considers a decreasing returns to scale (quadratic) firm production function. Here, we show that central components of the optimal policy profiles we derived, as represented by equations (36), (37) and (40), are robust to the using a constant returns to scale production function. Instead of $Y=\left(A-\frac{k}{2}\right) k$, we now replace (10) with

$$
Y=A k
$$

Following the same steps as in the main text, we obtain the following outcomes for optimal policies in ce

$$
\begin{aligned}
\theta^{c e} & =\frac{1+\rho(A-\phi-1)}{2} \\
r_{c b d c}^{c e} & =0
\end{aligned}
$$

and in nce

$$
\begin{aligned}
\theta^{n c e} & =\frac{2+\rho(A-\phi-1)}{3} \\
r_{c b d c}^{n c e} & =0
\end{aligned}
$$

Thus, the optimal unconstrained CBDC interest rate remains zero, in both ce and nce. Moreover, the CBDC is optimally made more similar to cash (i.e., to help preserve bank deposits) when the value of bank intermediation, $(A-\phi)$, rises. ${ }^{37}$

\footnotetext{
${ }^{37}$ Decreasing and constant returns to scale production functions do lead to a different bank response to CBDC competition. Under decreasing returns to scale, banks push back against the competition through higher deposit rates (and also lending rates in Appendix C.3). Instead, in the constant returns to scale setup, $r_{d}=A-\phi-1$ and therefore the deposit rate is irresponsive to $\theta$ and $r_{c b d c}$
} 


\section{C.2 Anonymity externalities}

In this extension, we consider the possibility that anonymous means of payment, like cash, are associated with negative externalities, due to the potential for illicit activities. There can be legitimate reasons that households desire anonymous forms of money, but by providing for that demand, the illicit uses of anonymity are also bolstered. ${ }^{38}$ In particular, we now let the utility of household $i$ be given by

$$
U_{i}(j)=\rho C_{j}-\left|x_{j}-i\right|-\eta_{j}-\beta \int_{n \neq i} x_{j(n)} d n
$$

where $\beta \int_{n \neq i} x_{j(n)} d n$ captures the notion of negative externalities from anonymous means of payment. Here, $n \in[0,1]$ represents "all other households". ${ }^{39}$ While every household with $i>0$ likes anonymity in her own means of payments, every household also dislikes anonymity in other households' transactions. The weight $\beta \in[0,1]$ represents the extent to which the household dislikes others' anonymity in payments transactions.

Following the same steps as before, we derive unconstrained optimal policies as

$$
\begin{aligned}
\theta^{c e} & =\frac{2+\rho(2(A-\phi)-1)-\beta(2+\rho)}{4+3 \rho-\beta(4+\rho)} \\
r_{c b d c}^{c e} & =-2 \frac{\beta}{4+\rho} \frac{(A-\phi)(4+\rho)-2(3+\rho)}{4+3 \rho-\beta(4+\rho)}
\end{aligned}
$$

which nest the solutions in (36) and (40) for $\beta=0 .{ }^{40}$ The most interesting aspect of these solutions is that, for any $\beta>0, r_{c b d c} \neq 0$ is now optimal, even when network effects play no role. Depending on parameter values, $r_{c b d c}^{c e}$ can be either positive or negative. In particular, in relation to the value of bank intermediation, $r_{c b d c}^{c e}$ moves inversely with $\theta^{c e}$ : A higher value of bank intermediation leads to a more cash-like optimal CBDC design and lower (including possibly negative) CBDC rates.

This inverse relation between optimal CBDC rates and optimal CBDC design parameter $\theta$ is intuitive, and derives from a ranking of forms of payment according to their anonymity externalities: cash is worst, deposits are best, and CBDC is somewhere in between, depending on its design. When CBDC design is optimally quite similar to cash, then it is also optimal to have negative $\mathrm{CBDC}$ rates, to push more households into deposits, and limit the anonymity externalities induced by the CBDC. Instead, when CBDC design is more similar to deposits, then a positive CBDC rate is optimal, to help attract more households away from cash.

\footnotetext{
${ }^{38}$ The magnitude of negative externalities from cash is a topic of intense debate (Engert et al., 2018; McAndrews, 2017; Rogoff, 2016; Wright et al., 2017).

${ }^{39}$ Given that each individual agent is atomistic, the space of all agents excluding one agent remains defined on $[0,1]$.

${ }^{40}$ The same holds for the nce solutions. These are not shown here in the interest of brevity, but are available on request.
} 


\section{C.3 Bank market power}

We now consider banks that compete à la Cournot in the loans market, taking the actions of other banks as given. Each bank therefore internalizes that total loans and the interest rates on those loans depend on its individual lending as follows

$$
\begin{aligned}
L & =l+(1-\nu) L \rightarrow \frac{\partial L}{\partial l}=1 \\
\frac{\partial R}{\partial l} & =\frac{\partial R}{\partial L}=-1
\end{aligned}
$$

where $\frac{\partial R}{\partial L}=-1$ comes from equation (12). Here, $\nu$ represents the extent of bank market power, with the extremes of $\nu=0$ and $\nu=1$ representing, respectively, perfect competition (i.e., our baseline model) and a monopoly.

The bank's profit maximization problem is given by

$$
\max _{l}\left\{\left(R(l)-r_{d}\right) l\right\}
$$

where the bank recognizes the dependence of loan rates on an individual bank's lending decision: $R$ depends on $l$. This yields the first order condition

$$
R(l)+\frac{\partial R(l)}{\partial l} l=r_{d}
$$

Moreover, deposit market equilibrium is derived from $D=L$, where $D$ is from $s_{d}$ in (19):

$$
L=\frac{\rho\left(r_{d}-r_{c b d c}\right)+\theta}{2}
$$

Together, (12), (62), and (63) provide three equations in three unknowns, $L, R$ and $r_{d}$. Replacing $\frac{\partial R}{\partial l}=-1$ from (60), and $l=\nu L$, we can solve this to attain

$$
\begin{aligned}
L & =\frac{\rho\left(A-1-r_{c b d c}-\phi\right)+\theta}{2+\rho(1+\nu)} \\
R & =A-\phi-1-\frac{\rho\left(A-1-r_{c b d c}-\phi\right)+\theta}{2+\rho(1+\nu)} \\
r_{d} & =\frac{2(A-1-\phi)+(1+\nu)\left(\rho r_{c b d c}-\theta\right)}{2+\rho(1+\nu)}
\end{aligned}
$$

Following the same steps as before, we again derive welfare and, from there, optimal policies

$$
\begin{aligned}
\theta^{c e} & =\frac{8+2 \rho(2 \nu+(A-\phi)(4+\rho+2 \rho \nu)-1)-\rho^{2}(1+(2-\nu) \nu)}{16+3 \rho^{2}(1+\nu)^{2}+8 \rho(2+\nu)} \\
r_{c b d c}^{c e} & =-2 \nu \frac{1+3 \rho(A-1-\phi)}{16+3 \rho^{2}(1+\nu)^{2}+8 \rho(2+\nu)}
\end{aligned}
$$


where for $\nu=0$ we retrieve our earlier solutions for optimal policies in (36) and (40). Indeed, by comparing the above expressions to (36) and (40), we can see the direction in which $\nu>0$ pulls optimal policies. That is, using the expressions for $\theta^{c e}$ and $r_{c b d c}^{c e}$ in (67) and (68), we numerically obtain that, over the parameter ranges in (17):

$$
\begin{aligned}
\inf \theta^{c e}-\left.\theta^{c e}\right|_{\nu=0} & =-\frac{279}{5372}, \sup \theta^{c e}-\left.\theta^{c e}\right|_{\nu=0}=0 \\
\inf r_{c b d c}^{c e}-\left.r_{c b d c}^{c e}\right|_{\nu=0} & =-\frac{35}{163}, \sup r_{c b d c}^{c e}-\left.r_{c b d c}^{c e}\right|_{\nu=0}=0
\end{aligned}
$$

and therefore $\nu>0$ means that both $\theta^{c e}$ and $r_{c b d c}^{c e}$ are lower than with $\nu=0$. This emanates from the fact that greater market power in lending helps insulate banks from the negative impact of a CBDC. Although increased competition for retail funding still drives up banks' deposit rates, banks with market power partly compensate by also raising loan rates. In view of banks' increased ability to withstand the impact of a CBDC, the optimal CBDC design moves closer to deposits (lower $\theta$ ), although the policy maker partly insulates the impact of this move by also cutting $\mathrm{CBDC}$ rates into negative territory.

\section{C.4 Alternate equilibria under suboptimal policies}

Table 1 listed three equilibria that do not occur under optimal policies. However, these equilibria can come about if policies are set suboptimally.

CBDC and cash Per Lemma 2, deposits never vanish under optimal policies. This is intuitive, since without deposits, our model yields zero intermediation, and the production of consumption goods shuts down. Nevertheless, it is easy to show that suboptimal policies could yield this equilibrium. For instance, for $\theta=0$, if the CBDC rate is set such that

$$
r_{c b d c}>A-\phi-1
$$

then this ensures that $r_{c b d c}>r_{d}$ (by equation (23)), while the payments profile $(\theta=0)$ is equivalent to deposits. Hence, the CBDC strictly dominates deposits in this case: no household would choose to hold deposits.

CBDC only Any arbitrarily high $r_{c b d c}$ would kill off both deposits and cash. Households would be paying for these CBDC interest payments through the lump-sum tax $T$, and therefore this scenario brings only disadvantages to households, who lose payment instrument variety and the productive benefits of bank intermediation, without gaining anything in return.

Cash and deposits There are three ways that a suboptimally designed CBDC could lead a situation where the design constraint (15) is violated such that there is no uptake of CBDC, and only 
cash and deposits are in use. First, CBDC could be designed in such a way that it is strictly dominated by cash, and violates (44). Second, CBDC design could imply that bank deposits are a strictly preferred form of payment, which occurs when (45) is violated. Third, even if the CBDC is not strictly dominated by cash or deposits, its design could be such that network effects prevent the buildup of a critical mass of CBDC users (15).

To give a concrete example, we replace $r_{d}$ from (23) into (45). This yields

$$
\left(\frac{1+\rho}{\rho}\right) \theta+r_{c b d c}>A-\phi-1
$$

which means that when the policy combination $\left(\theta, r_{c b d c}\right)$ is set such that the condition above is violated, as for example for a sufficiently negative $r_{c b d c}$, deposits strictly dominate CBDC.

\section{Deriving a linear city of payments preferences}

This appendix provides a stylized model highlighting how a linear-city model of payments preferences can be derived from microfoundations. The model is based on the notion that payments privacy can have value for households, when their digital transactions data can be used by private companies with monopoly power. We concentrate on a simple setup with cash and deposits only, and show how a "line" between these can arise endogenously, including a cutoff that determines household sorting. Once a spectrum of this sort is derived, formulating the intermediate case of a CBDC is a relatively straightforward extension. ${ }^{41}$

In this model, deposit-based payments are processed by a fintech provider (or a bank that has a similar business model), which is capable of tracking all transactions and is legally unencumbered to use this data to its own benefit. The fintech company is also the sole provider of credit in the economy, and provides loans to households. Moreover, the only means that the fintech company has to assess the creditworthiness of its customers is by parsing their transactions data. For simplicity, we abstract from explicitly modeling deposit and lending markets and interest rates here, and instead focus purely on household choice based on the characteristics of deposits versus cash.

There are two types of products for households to purchase in this economy: $G$ (Good) and $B$ (Bad), where $B$ can be considered a type of sin product, such as alcoholic beverages or cigarettes. Credit quality is inferred from the share of its income that a households spends on $G$. We assume identical incomes across households, and each household $i$ determines what fraction $\gamma(i)$ to spend on good $G$. Each household has a preferred share of its income that it would like spend on each type of product: we denote by $p(i)$ the ideal fraction of household $i$ 's income spent on good $G$. Households are heterogeneous in their ideal consumption patterns. In particular, households are uniformly distributed on $p(i) \in[0,1]$. Moreover, any distance between a household's

\footnotetext{
${ }^{41}$ See also Garratt and van Oordt (2019), who develop a payments model with privacy as a public good, where each consumer fails to internalize that her payments data is used to price discriminate among future consumers, and privacy in government issued electronic cash can create social value.
} 
ideal and actual consumption allocation, comes at a quadratic disutility cost to the household: $(\gamma(i)-p(i))^{2}$.

The key distinction between cash and deposits here, is that deposit transactions are monitored, while cash transactions are not. Monitoring matters because of the credit scores being assigned to households by the fintech company. For households using cash, the company cannot assign individualized credit scores, but rather uses an aggregate credit score, based on the consumption pattern of the average cash user. That is, all cash users are pooled together, in this respect. Instead, deposit using households are differentiated by the fintech company according to their own purchase behavior.

Importantly, once households use deposits for any fraction of their payments, they are unable to hide their overall purchase pattern from the fintech company. Endogenously, the model contains full revelation, because households have known, identical incomes. ${ }^{42}$ If the fintech company observes a depositor using only a fraction $\gamma(i)$ of income, and fully using it on $G$, then the company infers that the household used the rest of its income to purchase $B$ using cash. It is in this sense that deposits and cash cannot be effectively mixed: while the household is technically capable of mixing, the choice for using deposits at all, immediately implies full revelation: payments privacy is undiversifiable.

The aim of this appendix is purely qualitative, and as such we choose simple functional forms to highlight the relevant tradeoff. In particular, we let credit scores be a linear function of $\gamma(i)$ (for depositors) and assume that the utility derived from a higher credit score also enters linearly in the household's utility function. Household utility is given by

$$
U(i)=\lambda E[\gamma(i) \mid j(i)]-(\gamma(i)-p(i))^{2}
$$

where $j(i)$ is household $i$ 's chosen form of money, namely either $d$ (deposits) or $c$ (cash), $\lambda$ is a parameter that weighs the utility value of the welfare score as compared to approximating the household's ideal consumption shares, and

$$
E[\gamma(i) \mid j(i)]=\left\{\begin{array}{c}
\gamma(i) \text { if } j(i)=d \\
\widehat{\gamma} \text { if } j(i)=c
\end{array}\right.
$$

where $\widehat{\gamma}$ equals the average share of $G$ purchased by cash holders. Since households are atomistic, a given cash holder will always consume exactly the same as her bliss point: $\gamma(i)=p(i)$ when $j(i)=c$.

Instead, a depositor will solve the following optimization problem

$$
\max _{\gamma(i)}\left\{\lambda \gamma(i)-(\gamma(i)-p(i))^{2}\right\}
$$

\footnotetext{
${ }^{42}$ More generally, the underlying assumption can be seen as a requirement on deposit-opening households to reveal their income to the fintech provider.
} 
leading to optimal consumption share of $G$

$$
\gamma(i)=\frac{\lambda}{2}+p(i)
$$

where $\frac{\lambda}{2}$ parameterizes the extent of overconsumption of $G$ induced by monitored transactions.

The choice between cash and deposits then boils down to a comparison of utility under household optimal consumption. A household chooses deposits over cash if and only if utility as a depositor (setting $\gamma(i)=\frac{\lambda}{2}+p(i)$ ) is greater than utility as a cash holder (which equals $\lambda \widehat{\gamma}$ ). This becomes the following condition for choosing deposits:

$$
\frac{\lambda}{4}+p(i)>\widehat{\gamma}
$$

which can also be written as

$$
p(i)>\widehat{\gamma}-\frac{\lambda}{4}=\bar{p}
$$

This implies a sorting of households, such that households with $p(i)>\bar{p}$ choose deposits, while households with $p(i)<\bar{p}$ choose cash. That is, those households whose preferences favor a relatively large share of $G$ consumption, are more eager to engage in a full revelation relationship with the fintech provider, in order to reap the benefits of an improved credit score. Instead, households with a relatively larger preference for consuming $B$, choose cash, opting out of a depositor relationship with the fintech provider that effectively "forces" them to overconsume $G$ in order to appear more creditworthy. Overall, then, this model shows that heterogeneity in consumption preferences can translate into heterogeneous payment instruments choice. 